\title{
Reorganization of a marine trophic network along an inshore-offshore gradient due to stronger pelagic-benthic coupling in coastal areas
}

\author{
Kopp Dorothée ${ }^{1,2,3, *}$, Lefebvre Sébastien ${ }^{2}$, Cachera Marie ${ }^{2,3}$, Villanueva Ching-Maria ${ }^{3}$, \\ Ernande Bruno ${ }^{3}$
}

\footnotetext{
${ }^{1}$ Ifremer, Unité de Sciences et Technologies halieutiques, Station de Lorient, 8 rue François Toullec, F56325 Lorient Cedex, France

${ }^{2}$ Laboratoire d'Océanologie et de Géosciences (UMR CNRS 8187 LOG), Université de Lille 1, sciences et technologies, Station Marine de Wimereux, 28 Avenue Foch, 62930 Wimereux, France

${ }^{3}$ Ifremer, Laboratoire Ressources Halieutiques, 150 Quai Gambetta BP 699, F-62321 Boulogne-surMer, France
}

* Corresponding author : Dorothée Kopp, tel.: + 33297873800 ; fax: +33297873836 ; email address : dorothee.kopp@ifremer.fr

\begin{abstract}
:
Recent theoretical considerations have highlighted the importance of the pelagic-benthic coupling in marine food webs. In continental shelf seas, it was hypothesized that the trophic network structure may change along an inshore-offshore gradient due to weakening of the pelagic-benthic coupling from coastal to offshore areas. We tested this assumption empirically using the eastern English Channel (EEC) as a case study. We sampled organisms from particulate organic matter to predatory fishes and used baseline-corrected carbon and nitrogen stable isotope ratios $(\delta 13 \mathrm{C}$ and $\delta 15 \mathrm{~N})$ to determine their trophic position. First, hierarchical clustering on $\delta 13 \mathrm{C}$ and $\delta 15 \mathrm{~N}$ coupled to bootstrapping and estimates of the relative contribution of pelagic and benthic carbon sources to consumers' diet showed that, at mesoscale, the EEC food web forms a continuum of four trophic levels with trophic groups spread across a pelagic and a benthic trophic pathway. Second, based on the same methods, a discrete approach examined changes in the local food web structure across three depth strata in order to investigate the inshore-offshore gradient. It showed stronger pelagic-benthic coupling in shallow coastal areas mostly due to a reorganization of the upper consumers relative to the two trophic pathways, benthic carbon sources being available to pelagic consumers and, reciprocally, pelagic sources becoming accessible to benthic species. Third a continuous approach examined changes in the mean and variance of upper consumers' $\delta 13 \mathrm{C}$ and $\delta 15 \mathrm{~N}$ with depth. It detected a significant decrease in $\delta 13 \mathrm{C}$ variance and a significant increase in $\delta 15 \mathrm{~N}$ variance as depth increases. A theoretical two-source mixing model showed that an inshore-offshore decrease in the pelagic-benthic coupling was a sufficient
\end{abstract}


condition to produce the $\delta 13 \mathrm{C}$ variance pattern, thus supporting the conclusions of the discrete approach. These results suggest that environmental gradients such as the inshore-offshore one should be accounted for to better understand marine food webs dynamics.

\section{Highlights}

- Marine food web is reorganized along a seaward gradient in the English Channel. Stronger coupling of the pelagic and benthic pathways from offshore to the coast. \ Shift of pelagic predators to the benthic pathway in shallow areas. Adaptive foraging of pelagic predators may explain food web reorganization.

Keywords : Food web, Spatial variation, Stable isotope, Megatidal shelf ecosystem 


\section{Introduction}

The structure of food webs has been the subject of increasing interest during the past two decades. Research questions on food web structure lie in the field of ecological networks that aims at understanding how community structure and trophic interactions affect ecosystem functioning (Ings et al., 2009). Among the ecological functions studied are trophic resource acquisition and biomass production, and their dependence on biodiversity and trophic interactions in food webs (Duffy et al., 2007). Studies of the structure of food webs are thus essential to predict the response of ecosystems to the effect of global change on biodiversity. Nevertheless, studies of trophic network structure at large spatial and taxonomical scales in marine ecosystems remain relatively scarce (e.g. Woodland and Secor, 2013).

Ings et al. (2009) considered the study of networks along environmental gradients as well as from local to regional scales as "fruitful avenues". However, there is a current lack of knowledge on the way food web structure is affected by variation in environmental conditions along gradients (but see Dézerald et al., 2013; Woodland and Secor, 2013). Most of the time, when trophic network structure is studied at a sufficiently large geographical scale to address this issue, only some compartments of the food web are considered in order to ensure a large spatial coverage and a reliable sampling effort (e.g. pelagic fishes and zooplankton; SholtoDouglas et al., 1991 or top-predators and their prey; Revill et al., 2009). Then, the targeted species or compartments are most often keystone species or strong interactors as their loss or removal could cause dramatic changes in communities (e.g. Paine, 1969). However, it is essential to consider most species of a community, as weak interactors, the removal or addition of which is assumed to cause indiscernible changes, may have a preponderant role in maintaining community stability (Berlow, 1999). Due to the multiplicity of ecological links established by weak interactors in species-rich communities, the resulting complex network is 
71 able to buffer variations in keystone species (Brose et al., 2005) and to sustain community

72 stability under environmental variations such as stress and disturbance (Worm and Duffy, 2003). Another approach is to describe all the interactors of the food web but at a lower spatial resolution. For instance, investigations have often focused on small dedicated areas such as coastal nursery grounds (Rodríguez-Graña et al., 2008), marine protected areas (Vizzini and Mazzola, 2009; Albouy et al., 2010) or emblematic zones such as reef areas (Thomas and Cahoon, 1993; Jennings et al., 1997). However, such limited geographical scale automatically prevents from addressing the question of the effect of environmental gradients. Among others, a food web"s structure is important as it determines its own dynamics, be it in terms of energy or material fluxes (Dunne, 2006), but also its properties such as resilience and stability. Notably, the relationship between diversity and stability depends strongly on food web structure as for a given species richness food web stability is expected to depend on connectance, i.e. the fraction of realized trophic links among all the possible ones (Rooney and McCann, 2012). Therefore, knowledge of variations in food webs ${ }^{\text {ee }}$ structure along environmental gradients is essential in understanding their dynamics and evaluating their stability and resilience to natural and anthropogenic disturbances. Recent theoretical considerations highlighted the importance of considering the coupling between pelagic and benthic pathways in marine food webs to understand their structure (Woodland and Secor, 2013), functioning (Blanchard et al., 2009) and resilience to perturbations (Blanchard et al., 2011). Notably, pelagic food webs are supposed to be more strongly sizestructured, both in terms of trophic level (TL) and abundance, than benthic ones, because large predators eat smaller prey in the former (Cohen et al., 1993), whereas predators share unstructured and more diverse resources in the latter (Maxwell and Jennings, 2006). The pelagic-benthic coupling is therefore specifically important in understanding the structure of trophic networks in continental shelf seas where pelagic and benthic animals co-occur 
spatially. Physical proximity between pelagic and benthic species and weaker physical

97 barriers such as thermoclines in shallow, mixed continental shelf waters may indeed allow a

98 stronger benthic-pelagic coupling. Based on these theoretical premises, we hypothesized that 99 in shelf seas (i) the coupling between pelagic and benthic pathways weakens from coastal to 100 offshore areas, which results into changes in the trophic network structure along the inshore101 offshore gradient; and (ii) these changes imply that the food web structure estimated from 102 data varies according to the geographical scale considered, i.e. global versus local scale.

We tested these hypotheses empirically in the eastern English Channel (EEC) - a shallow continental shelf sea taken as a case study. To this end, we sampled the largest possible range of organisms, from particulate organic matter to large predatory fishes, with a large spatial grid covering $35000 \mathrm{~km}^{2}$ (Fig. 1). We used carbon and nitrogen stable isotopes analyses to determine species $^{\text {ee }}$ trophic position. Hierarchical clustering coupled to bootstrapping allowed us to identify trophic groups of species according to their isotopic ratios and thereby the trophic network structure at the scale of the whole sampling area (hereafter termed global scale). The strength of the benthic-pelagic coupling was assessed by estimating the relative contributions of pelagic and benthic sources of carbon to consumers' diet using a two-source mixing model. Then, we followed a discrete approach to test for an inshore-offshore gradient in the food web structure. Trophic groups and contributions of carbon sources were assessed using the same techniques but at the local scale, i.e. in three different depth strata distributed along the gradient. These are characterized by varying animal community composition and co-varying factors such as salinity, water temperature and soft 117 bottom features (Martin et al., 2010). Finally, we developed a continuous approach in which 118 we tested for an inshore-offshore gradient in the local food web structure through the 119 influence of depth on the distribution (mean and variance) of nitrogen and carbon isotopic 120 ratios of upper consumers (from secondary consumers upward, except for decapod 
121 crustaceans). The results of the continuous approach were completed and interpreted in terms

\section{Materials and methods}

\subsection{Study system and gradient approaches}

The eastern English Channel (EEC) is a shallow epi-continental sea located between England and France, which presents an inshore-offshore gradient in habitats from the coast to its central area (Vaz et al., 2007). After estimating the food web structure at the global scale, two approaches were used to study variations of the local food web structure along the inshore-offshore gradient, a discrete and a continuous one, both based on the use of depth as a proxy of the gradient. Depth is indeed strongly correlated with the distance to the coast in the EEC as well as with many environmental parameters (see below) and may be directly involved in the benthic-pelagic coupling due to its obvious effect on the proximity between the corresponding compartments.

- Discrete gradient approach

The EEC was sub-divided into three depth strata based on changes according to depth in the taxonomic composition of the community of vertebrates (fishes) and invertebrates (cephalopods and benthic epifauna) observed by trawling during the Channel Ground Fish

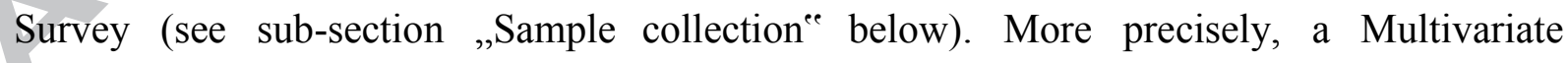
Regression Tree (MRT) of the invertebrate and vertebrate species presence/absence data matrix on depth was performed in order to identify depth thresholds at which the community composition changed significantly. MRT is a constrained clustering method that identifies clusters based on minimizing the within-group sums of squares but where partitioning occurs at successive thresholds of a constraining or explanatory variable, here depth (Borcard et al., 
146 2011). Computation of sums of squares was based on Euclidian distance. A first split occurred

at $20 \mathrm{~m}$ and a second one at $38 \mathrm{~m}$ delineating three depth strata between 0 and $20 \mathrm{~m}, 20$ and 38m, and 38 and $79 \mathrm{~m}$ (Fig. 1). These were characterized by different taxonomic compositions of the vertebrate and invertebrate community but also different physicochemical 150 features as these are known to co-vary with depth in the EEC. Salinity increases with depth as 151 the influence of continental freshwater fades away along the inshore-offshore gradient, 152 whereas average temperature along the water column decreases with increasing depth. 153 Sediment types also change from mud and fine sands in shallow waters through coarse sands 154 to gravels and pebbles in deeper areas as bed shear stress resulting from tidal currents 155 increases with depth (Martin et al., 2010).

- Continuous gradient approach

157 We complemented the discrete gradient approach by a continuous one, which consisted in 158 evaluating the influence of depth on the distribution (mean and variance) of nitrogen and

carbon isotopic ratios among all upper consumers (from secondary consumers upward, except for decapod crustaceans which were under-represented in offshore areas) of the food web in order to test for continuous changes in TL or trophic pathway along an inshore-offshore gradient. This provides another way to look at potential reorganization of the local trophic network structure in the EEC. This continuous approach based on observations was completed by a theoretical approach (see below $\$ 2.7)$.

\subsection{Sample collection}

Particulate organic matter, zooplankton, epifaunal invertebrates and fishes were sampled in the EEC for the purpose of the present study and represented a total of $c a .900$ samples. Fishes and some epifaunal invertebrates were collected during the Channel Ground Fish Survey (October 2009) using a GOV demersal trawl with a cod-end of $10 \mathrm{~mm}$ stretched 

178

mesh, towed for $30 \mathrm{~min}$ at a speed of approximately 3.5 knots from R. V. "Gwen Drez" (Vaz et al., 2007). Other samples of epifaunal invertebrates were gathered during the COMOR survey (June 2010) using a French dredge towed for 5 to 6 minutes at a speed of approximately 2.5 knots from R. V. "Thalia” (Delpech et al., 2007). As our samples were 175 collected by bottom trawling and dredging, small epifauna was underrepresented in the 176 samples and infauna was almost absent. Zooplankton was sampled during the International 177 Bottom Trawl Survey (February 2010) using a WP2 zooplankton net (Tranter and Smith,

\subsection{Stable isotope analysis (SIA)}

Stable isotopes of carbon and nitrogen in tissues of organisms were used to examine consumers' trophic ecology. $\delta^{15} \mathrm{~N}$ values were used to define the trophic level of consumers and $\delta^{13} \mathrm{C}$ values were used to identify their position relative to the pelagic or the benthic trophic pathways (De Niro and Epstein, 1978). Tissues were prepared for SIA as follows: Whatman GF/F filters containing particulate organic matter (POM) were oven-dried and subsequently exposed to $\mathrm{HCl}$ vapour for 4 hours in order to remove carbonates (Lorrain et al., 2003). For zooplankton, after thawing samples in distilled water, copepods, fish larvae, and chaetognaths were hand-picked from the detritus-rich samples and prepared whole. When necessary, they were pooled by areas to ensure reliable $\mathrm{C}$ and $\mathrm{N}$ isotopic measurements. For invertebrates, processing varied according to taxon. For annelids, analyses were done on the 
remaining tissues once the digestive tracts and jaws were removed under a dissecting microscope. Muscle samples were taken from the abdomen of shrimps, the chelipeds of crabs and paguroids, the adductor muscle of bivalve molluscs, the foot of Buccinum undatum and Crepidula fornicata, and the mantle of cephalopods. Gonads were used for sea urchins. For fishes, a sample of white dorsal muscle was dissected (Pinnegar and Polunin, 1999). After dissection, tissue samples of all benthic taxa were washed with distilled water in order to prevent any contamination by sediment carbonates.

All samples were frozen at $-80^{\circ} \mathrm{C}$ before freeze-drying. Each dried sample was then ground into a homogeneous powder using a mixer mill. Approximately $2 \mathrm{mg}$ of powder was weighed into small tin cups, and determination of $\delta^{15} \mathrm{~N}, \delta^{13} \mathrm{C}$ and $\%$ content of $\mathrm{C}$ and $\mathrm{N}$ was carried out by Elemental Analysis Isotope Ratio Mass Spectrometry by Iso-analytical Ltd (Crewe, UK) using a Europa Scientific elemental analyser coupled to a Europa Continuous Flow Isotope Ratio Mass Spectrometer. In the present study, isotope ratios are reported in delta notation as per international standards: PeeDee belemnite carbonate for $\delta^{13} \mathrm{C}$ and atmospheric nitrogen for $\delta^{15} \mathrm{~N}$. Data were corrected using working standards (bass muscle, bovine liver, nicotinamide; $\mathrm{SD}<0.2 \%$ for both $\delta^{13} \mathrm{C}$ and $\left.\delta^{15} \mathrm{~N}\right)$ that were previously calibrated against International Atomic Energy Agency (IAEA) standards. For all taxa, except mackerel (Scomber scombrus), the mean observed C:N ratio was lower than 3.5, the value above which lipid normalization is recommended (Post et al., 2007). Different techniques are available to account for the influence of lipid content on $\delta^{13} \mathrm{C}$ ratios (Sweetings et al., 2006; Logan et al.; 2008). Normalization of $\delta^{13} \mathrm{C}$ ratios for mackerel was performed according to the following equation (Post et al., 2007):

$\delta^{13} \mathrm{C}_{\text {normalized }}=\delta^{13} \mathrm{C}_{\text {untreated }}-3.32+0.99 \mathrm{C}: \mathrm{N}$ 
The $\delta^{15} \mathrm{~N}$ and $\delta^{13} \mathrm{C}$ values of a species provide information about its trophic level and

pathway relative to a baseline. A suspension-feeding bivalve, queen scallop Aequipecten opercularis, was chosen as the trophic baseline for this study (Jennings and Warr, 2003). Using a primary consumer as a baseline has the advantage over primary producers such as phytoplankton of buffering short term variations in isotopic values due to seasonality in environmental factors or any other short-term source of temporal variability. One difficulty though is that isotopic values of the trophic baseline, and thus of species at higher trophic levels, may vary spatially due to environmental gradients. Specifically, along the inshoreoffshore gradient there is a diminishing influence of terrigenous influx of nutrients and detritus that are characterized by $\delta^{15} \mathrm{~N}$ and $\delta^{13} \mathrm{C}$ ratios different from those of oceanic material. It results that observed isotopic values of higher trophic level species (here consumers) must be corrected for spatial variation in baseline values.

Unfortunately, the spatial coverage of our A. opercularis samples was insufficient (12 sampling sites; Fig. S1) to estimate properly spatial variation in $\delta^{15} \mathrm{~N}$ and $\delta^{13} \mathrm{C}$ baseline values. To overcome this problem, we used published $\delta^{15} \mathrm{~N}$ and $\delta^{13} \mathrm{C}$ values of $A$. opercularis sampled with a better spatial coverage (23 sampling sites; Fig. S1) in summer 2001 (see Jennings and Warr, 2003 and Barnes et al., 2009 for more details about the sampling protocol and available isotopic). Published isotopic ratios at our disposal were averages of 3 to 6 individual values per sampling site (median $=5$ ) except for one site with only 1 individual value. We used these to predict $\delta^{15} \mathrm{~N}$ and $\delta^{13} \mathrm{C}$ baseline values at all our sampling sites using a geostatistical interpolation technique, namely kriging (Diggle and Ribeiro, 2007; see Supplementary Material 1 for the detailed procedure). Despite our A. opercularis samples and 243 published data were collected in different years, the spatial structuring of isotopic values was 244 similar as predicted values at our sampling sites and observed baseline values from our 245 samples correlated significantly $\left(\delta^{15} \mathrm{~N}: \mathrm{r}=0.58, \mathrm{n}=19, \mathrm{t}_{17}=2.9452, \mathrm{p}=0.0090 ; \delta^{13} \mathrm{C}: \mathrm{r}=0.74\right.$, 
$\mathrm{n}=19, \mathrm{t}_{17}=4.5073, \mathrm{p}=0.0003$; Fig. S1). For both nitrogen and carbon, the isotopic value of each consumer sample was then corrected by subtracting the predicted baseline value at the sampling location and by adding the mean predicted baseline value across all sampling sites. All isotopic ratios of consumers used in further analyses are corrected ones.

\subsection{Trophic level and trophic sources}

$\delta^{15} \mathrm{~N}$ and $\delta^{13} \mathrm{C}$ are enriched from a prey to its predator (trophic fractionation) by 2.5 4.5\% (mean 3.4\%o; Minagawa and Wada, 1984; Post, 2002) and 1-2\%o (mean 1.5\%o; De Niro and Epstein, 1978; Wada et al., 1991), respectively. Therefore, we depicted the pelagic and the benthic trophic pathway according to the limits of the ranges of isotopic ratios expected for the trophic transfer of pelagic and benthic organic matter (Darnaude et al. 2004; Fig. 2). We used the maximum trophic increases of $+4.5 \%$ in $\delta^{15} \mathrm{~N}$ and the minimum of $+1 \%$ in $\delta^{13} \mathrm{C}$ to delimit the upper range of each trophic pathway, and the minimum of $+2.5 \%$ in $\delta^{15} \mathrm{~N}$ and the maximum of $+2 \%$ in $\delta^{13} \mathrm{C}$ to delimit the lower range. The isotopic ratios of a pelagic primary consumer, namely copepods, and of a benthic primary consumer, namely $A$. opercularis, were used as starting point of the range for the pelagic and the benthic pathway, respectively.

As the $\delta^{15} \mathrm{~N}$ value provides indication of the trophic level of a consumer, the TL of each species was calculated following the equation from Post (2002):

$$
\mathrm{TL}_{\text {species }}=\left(\delta^{15} \mathrm{~N}_{\text {species }}-\delta^{15} \mathrm{~N}_{\text {base }}\right) / \Delta \mathrm{N}+\mathrm{TL}_{\text {base }}
$$

266 where $\Delta \mathrm{N}$ is the assumed average trophic fractionation corresponding to $1 \mathrm{TL}$ for $\delta^{15} \mathrm{~N}$, 267 estimated at 3.4\% (Minagawa and Wada, 1984), $\delta^{15} \mathrm{~N}_{\text {species }}$ is the mean value of the focal 268 species, $\delta^{15} \mathrm{~N}_{\text {base }}$ is the mean value of a species close to the base of the food web chosen as 269 trophic baseline, here $A$. opercularis, and $\mathrm{TL}_{\text {base }}$ is its trophic level. As a primary consumer the trophic level of $A$. opercularis was set to $\mathrm{TL}_{\mathrm{base}}=2$. The approximate standard errors $(\sigma)$ 
271 of species TLs were calculated based on the standard errors of $\delta^{15} \mathrm{~N}_{\text {species}}, \delta^{15} \mathrm{~N}_{\text {base }}$ and $\Delta \mathrm{N}$ (see

Supplementary Information 2 for details on the derivation)

$$
\sigma_{\mathrm{TL}_{\text {species }}}=\left(\frac{1}{\Delta \mathrm{N}^{2}}\left(\sigma_{\delta^{15} \mathrm{~N}_{\text {species }}}^{2}+\sigma_{\delta^{15} \mathrm{~N}_{\text {base }}}^{2}\right)+\frac{\left(\delta^{15} \mathrm{~N}_{\text {species }}-\delta^{15} \mathrm{~N}_{\text {base }}\right)^{2}}{\Delta \mathrm{N}^{4}} \sigma_{\Delta \mathrm{N}}^{2}\right)^{1 / 2} .
$$

274 Equation (3) accounts for variability in observed $\delta^{15} \mathrm{~N}$ values $\left(\sigma_{\delta^{15} \mathrm{~N}_{\text {species }}}\right.$ and $\left.\sigma_{\delta^{15} \mathrm{~N}_{\text {base }}}\right)$ but 275 also for uncertainty in trophic fractionation value $\left(\sigma_{\Delta \mathrm{N}}\right)$. While $\sigma_{\delta^{15} \mathrm{~N}_{\text {species }}}$ and $\sigma_{\delta^{15} \mathrm{~N}_{\text {base }}}$ 276 were estimated from the data directly, $\sigma_{\Delta \mathrm{N}}$ was estimated by assuming that the range of 277 possible fractionation values for nitrogen $2.5-4.5 \%$ covers $99 \%$ of the distribution and that 278 this distribution is Gaussian, which yields a standard deviation of $\sigma_{\Delta \mathrm{N}}=0.333 \%$.

We calculated the contributions of pelagic and benthic sources of carbon to fish and cephalopod diet using a two-source mixing model with the $\delta^{13} \mathrm{C}$ ratios of copepods and $A$. opercularis as the $\delta^{13} \mathrm{C}$ ratios of the pelagic and the benthic carbon source, respectively. Since isotope mixing models can be highly sensitive to uncertainty surrounding the mean isotopic ratios of sources, we used a mixing model developed by Phillips and Gregg (2001), which incorporates the observed variation in source isotopic values to calculate the standard errors of contribution estimates. We calculated the proportion of benthic carbon $(\alpha)$ in fish diet using Phillips and Greggee (2001) equation:

$\alpha=\left(\delta^{13} \mathrm{C}_{\text {species }}-\delta^{13} \mathrm{C}_{\mathrm{P}}\right) /\left(\delta^{13} \mathrm{C}_{\mathrm{B}}-\delta^{13} \mathrm{C}_{\mathrm{P}}\right)$

288 with $\delta^{13} \mathrm{C}_{\text {species}}, \delta^{13} \mathrm{C}_{\mathrm{B}}$ and $\delta^{13} \mathrm{C}_{\mathrm{P}}$ the mean $\delta^{13} \mathrm{C}$ values of consumer species, benthic and 289 pelagic carbon sources respectively. The $\delta^{13} \mathrm{C}$ value of the consumer $\left(\delta^{13} \mathrm{C}_{\text {species }}\right)$ was 290 corrected for an average trophic fractionation of $\Delta \mathrm{C}=1.5 \%$ per trophic level above the trophic level of the sources, i.e. 2:

$292 \quad \delta^{13} \mathrm{C}_{\text {species }}=\delta^{13} \mathrm{C}_{\text {species }}^{\prime}-\Delta \mathrm{C}\left(\mathrm{TL}_{\text {species }}-2\right)$ 
with $\delta^{13} \mathrm{C}_{\mathrm{species}}^{\prime}$ the original value of the consumer and $\mathrm{TL}_{\text {species }}$ its trophic level. The approximate standard error of $\alpha$ was computed according to Phillips and Gregge's (2001) equation modified to account for the correction for trophic fractionation (see Supplementary Information 2 for details on the derivation):

$$
\begin{aligned}
\sigma_{\alpha}= & \left(\left(\sigma_{\delta^{13} \mathrm{C}_{\text {species }}^{\prime}}^{2}+\Delta \mathrm{C}^{2} \sigma_{\mathrm{TL}_{\text {species }}}^{2}+\left(\mathrm{TL}_{\text {species }}-2\right)^{2} \sigma_{\Delta \mathrm{C}}^{2}\right.\right. \\
& \left.\left.+\alpha^{2} \sigma_{\delta^{13} \mathrm{C}_{\mathrm{B}}}^{2}+(1-\alpha)^{2} \sigma_{\delta^{13} \mathrm{C}_{\mathrm{P}}}^{2}\right) /\left(\delta^{13} \mathrm{C}_{\mathrm{B}}-\delta^{13} \mathrm{C}_{\mathrm{P}}\right)^{2}\right)^{1 / 2} .
\end{aligned}
$$

As for $\sigma_{\mathrm{TL}_{\text {species }}}$, this standard error accounts for variability in the data but also for uncertainty in fractionation value. Following the same reasoning as previously, if the range of possible fractionation values for carbon $1-2 \%$ covers $99 \%$ of the distribution and this distribution is Gaussian, the standard deviation is estimated as $\sigma_{\triangle \mathrm{C}}=0.167 \%$.

\subsection{Statistical analyses}

Trophic groups of species at meso- and local scales (discrete gradient approach) were identified by hierarchical clustering analysis on $\delta^{15} \mathrm{~N}$ and $\delta^{13} \mathrm{C}$ values using Ward"s minimum variance method (Ward Jr, 1963). This method is based on the linear model criterion of least squares and its objective is to define groups that minimize the within-group sum of squares.

Computation of within-group sums of squares is based on a Euclidean model. Given that sample size varied between taxa (from 3 to 63; Table 1), but that the intention was to account 310 for within-sample variation in isotopic ratios, hierarchical clustering was performed on a 311 bootstrapped matrix of distances between species that was computed as follows: since 312 minimum sample size was 3, 3 individuals per species were sampled with replacement, the 313 isotopic ratios of which were used as coordinates to compute a Euclidian distance matrix 314 between species after standardizing coordinates to 0 mean and unit variance. This procedure 315 was repeated 500 times, and the resulting distance matrices were averaged to obtain the 
316 bootstrapped distance matrix on which clustering was performed. The number of resampling

317 was sufficient to stabilize the values of the bootstrapped distance matrix. After clustering, the optimal number of clusters was assessed by visual inspection of the resulting dendrogram and confirmed using graphs of fusion level (Borcard et al., 2011).

The influence of depth (continuous gradient approach) on the mean and variance of $\delta^{15} \mathrm{~N}$ and $\delta^{13} \mathrm{C}$ ratios of upper consumers of the food web (continuous gradient approach) was analysed using generalized least squares models that can account for heteroscedastic variance of observations in linear regression models (Pinheiro and Bates, 2004). The following procedure was used (Zuur et al., 2009): first, a classical linear model was fitted to $\delta^{15} \mathrm{~N}$ and $\delta^{13} \mathrm{C}$ values with depth as a continuous explanatory variable, and residuals were inspected for normality and homoscedasticity. Residuals of both $\delta^{15} \mathrm{~N}$ and $\delta^{13} \mathrm{C}$ values exhibited clear heteroscedasticity in relation with depth. As a second step, a generalized least squares model was fitted with depth as a continuous explanatory variable of the mean and variance of $\delta^{15} \mathrm{~N}$ and $\delta^{13} \mathrm{C}$ values. For variance, several sub-models were tested: a linear, an exponential, and a power function of depth as well as a constant plus a power function of depth. The best variance model was chosen on the basis of the Akaike Information Criterion (AIC), and the significance of the effect of depth on variance was assessed by a likelihood ratio test between the classical linear model and the generalized least squares model that is supposed to follow a $\chi^{2}$ distribution under the null hypothesis. The significance of the effect of depth on the mean was assessed using an $F$ test on the basis of the generalized least squares model. Primary producers, primary consumers and decapod crustaceans were excluded from this approach 337 because the two first ones are known to present wider spread of isotopic ratios than high TL organisms (i.e. Chouvelon et al., 2012), and because our sampling procedure would have 339 induced bias as these three compartments were under-represented in offshore areas (Table 1). 
All analyses were performed in the statistical environment R ( R Development Core Team, 2012). Multivariate regression trees were performed with package mvpart (Therneau et al., 2013), geostatistical analyses were done with package GeoR (Ribeiro Jr and Diggle, 2001), and generalized least squares models were fitted with package nlme (Pinheiro et al., 2013). The data and $\mathrm{R}$ codes used in this study are available from the authors upon request.

\subsection{Theoretical two-source mixing model}

A theoretical two-source mixing model was developed to complement and interpret 348 the results of the continuous gradient approach on upper consumers. This model mimicked the 349 observed pattern in the contribution $\alpha$ of benthic carbon to upper consumers' diet according to 350 depth and predicted the resulting changes in the distribution (mean and variance) of upper 351 consumers' $\delta^{13} \mathrm{C}$ ratios with depth.

Two groups of upper consumers composed of 376 individuals each were modeled (752 upper consumers were observed in our samples). They differed in terms of their affinity for the pelagic and the benthic trophic pathway due to their position in the water column. This difference in affinity translated into different contributions $\alpha$ of benthic carbon to consumers' diet as observed in our data. $\alpha$ was therefore modeled as a truncated normal distribution between 0 and 1 with mean 0.3 for consumers with a pelagic affinity (observed mean=0.32) and 0.6 for those with a benthic affinity (observed mean=0.58). The weakening of the pelagicbenthic coupling along the seaward gradient was modeled as a logistic decrease in the variance of $\alpha$ from 0.06 to 0.02 with increasing depth, a pattern observed in our estimates of $\alpha$ (observed variances of $\alpha$ centered around its mean according to species affinity being equal to $0.06,0.03$ and 0.02 for stratum $0-19 \mathrm{~m}, 20-38 \mathrm{~m}$, and $38-78 \mathrm{~m}$, respectively). This agrees with the line of reasoning according to which, in shallow waters, physical proximity facilitates consumers' access to both pelagic and benthic carbon sources such that, because of 
opportunistic behavior, the contribution of the two carbon sources to diet, and thus $\alpha$, can vary greatly whatever the consumers' affinity. In contrast, in deeper areas, consumers will access to carbon sources according to their position in the water column and thus contributions $\alpha$ will be more narrowly centered around consumers' affinity. The benthic and pelagic carbon sources were modeled as having $\delta^{13} \mathrm{C}$ ratios varying according to normal distributions with means $-17.4 \%$ and $-21.1 \%$ and standard deviation $0.5 \%$ and $0.9 \%$ respectively, which corresponded to our observations for A. opercularis and copepods respectively. At each depth, each consumer $C$ was then attributed a contribution $\alpha_{C}$ of benthic carbon to its diet randomly drawn from the truncated normal distribution corresponding to its affinity. The consumer's $\delta^{13} \mathrm{C}$ value was then computed according to a two-source mixing model as $\delta^{13} \mathrm{C}_{\mathrm{C}}=\alpha_{\mathrm{C}} \delta^{13} \mathrm{C}_{\mathrm{B}}+\left(1-\alpha_{\mathrm{C}}\right) \delta^{13} \mathrm{C}_{\mathrm{P}}$, where the $\delta^{13} \mathrm{C}$ values of the benthic and pelagic carbon sources, $\delta^{13} \mathrm{C}_{\mathrm{B}}$ and $\delta^{13} \mathrm{C}_{\mathrm{P}}$ respectively, were randomly drawn from the corresponding normal distributions. The changes with depth in the resulting mean and variance of consumers' $\delta^{13} \mathrm{C}$ values were then inspected and compared to observed data. Any agreement between the observed and the predicted pattern in $\delta^{13} \mathrm{C}$ values would suggest that variation in the strength of the pelagic-benthic coupling was a sufficient condition to generate the pattern.

\section{Results}

\subsection{Global-scale trophic network structure in the eastern English Channel}

54 species, 3 pools of zooplankton and particulate organic matter (POM) were analysed for stable isotopic ratios. $\delta^{15} \mathrm{~N}$ values ranged from $7.5 \%$ to $17.2 \%$ with POM presenting the lowest $\delta^{15} \mathrm{~N}$ values, and a cephalopod, Loligo vulgaris, the largest ones (Table 1; Fig. 2). Organisms in the EEC formed a continuum of four tropic levels from POM $(\mathrm{TL}=1.8)$ to fishes and cephalopods ( $\max \mathrm{TL}=4.6$; Table 1$). \delta^{13} \mathrm{C}$ values ranged from $-21.5 \%$ 
to $-15.5 \%$ with considerable overlap notably among fish species (Fig. 2; Table 1). $\delta^{13} \mathrm{C}$ values varied greatly among primary consumers with deposit-suspension feeders exhibiting larger values than zooplankton (Table 1). The difference between $\delta^{13} \mathrm{C}$ values of pelagic (i.e. copepods $=-21.1 \% \pm 0.9)$ and benthic primary consumers (i.e. Aequipecten opercularis $=$ $-17.4 \%$ o \pm 0.5$)$ provided evidence for two trophic pathways in the EEC: a pelagic pathway rooted in POM on which zooplankton depends and a benthic pathway supplying benthic suspension feeders.

Hierarchical clustering performed on $\delta^{13} \mathrm{C}$ and $\delta^{15} \mathrm{~N}$ values illustrated that the trophic network of the EEC at the global scale could be sub-divided into 6 trophic groups, from POM to fishes and cephalopods (Fig. 2). Group 1 (mean $\delta^{15} \mathrm{~N} \pm \mathrm{SD}=7.55 \pm 2.35$; mean $\delta^{13} \mathrm{C} \pm \mathrm{SD}$ $=-21.53 \pm 1.32)$ corresponded to POM. Two groups of primary consumers could be distinguished: a pelagic one, Group $2\left(\delta^{15} \mathrm{~N}=9.96 \pm 1.48 ; \delta^{13} \mathrm{C}=-20.77 \pm 1.14\right)$, mainly composed of copepods (detailed about the taxa included in this group and in the following can be found in Fig. 2 and Table 1) and a benthic one, Group $3\left(\delta^{15} \mathrm{~N}=8.81 \pm 0.88 ; \delta^{13} \mathrm{C}=-17.75\right.$ $\pm 0.75)$, composed of benthic suspension feeders.

$\delta^{15} \mathrm{~N}$ values allowed further discrimination of organisms with a TL around 3 and two groups of secondary consumers could be distinguished: a pelagic one, Group 4, with low $\delta^{13} \mathrm{C}$ values $(-18.14 \pm 1.34)$ and a benthic one, Group 5 , exhibiting $\delta^{13} \mathrm{C}$ values $\left(\delta^{13} \mathrm{C} \pm \mathrm{SD}=\right.$ $-16.46 \pm 0.85)$ close to those of suspension feeders. Group 4 could be further sub-divided into three sub-groups: i) sub-group 4.1 mainly composed of carnivorous zooplankton and a zooplanktivorous fish ; ii) sub-group 4.2 formed by a mix of small zooplanktivorous pelagic fishes, crabs and benthic fishes and iii) sub-group 4.3 characterized by pelagic fishes. The 412 group of benthic secondary consumers, Group 5, mostly gathered elasmobranchs, flatfishes, 413 and crustaceans. 
Finally, a group of tertiary consumers, Group 6, with a TL around 4 was located at the

interface between the pelagic and the benthic pathway (mean $\delta^{13} \mathrm{C} \pm \mathrm{SD}=-17.08 \pm 0.85$ ). It could be sub-divided into two sub-groups: sub-group 6.1 formed by a mix of benthic and demersal fishes sub-group 6.2 mainly composed of large demersal fishes and cephalopods.

Dependency of the groups of upper consumers (4 to 6) on the pelagic and benthic trophic pathway as determined from the limits of the ranges of isotopic ratios expected for the trophic transfer of pelagic and benthic organic matter (dashed lines in Fig. 2) was confirmed by the estimates of pelagic and benthic carbon contributions to upper consumers ${ }^{\text {ee }}$ diet by the two-source mixing model: Group 4 belonged to the pelagic pathway with an average pelagic contribution to consumers ${ }^{\text {ee }}$ diet of 0.69 , whereas Group 5 depended on the benthic pathway with an average benthic contribution of 0.76 and Group 6 depended on both pathways with an average contribution of pelagic and benthic carbon of 0.59 and 0.41 , respectively.

\subsection{Local-scale trophic network structure in the eastern English Channel}

\subsubsection{Discrete gradient approach}

The trophic structure of upper consumers was altered in the shallow depth stratum (0$20 \mathrm{~m})$ compared to deeper strata $(20-38 \mathrm{~m}$ or $38-79 \mathrm{~m})$ and the global scale. Firstly, sub-group 4.2, mostly characterized by small planktivorous pelagic fishes, and group 5, comprising flatfishes and elasmobranchs, merged into a new group (Fig. 3A and S2). This was mostly due to species from sub-group 4.2, notably dragonet Callionymus lyra, pilchard Sardinus pilchardus and herring Clupea harengus, that were enriched in ${ }^{13} \mathrm{C}$ compared to deeper strata and the global scale. As a result, these species were positioned in the benthic pathway together with flatfishes in shallow waters (Fig. 3A) whereas they preferentially preyed upon

437 pelagic sources of carbon in deeper areas (Fig.3B). Results of the two-source mixing model confirmed this pattern. The benthic contribution to diet of C. lyra, C. harengus and $S$. 
pilchardus decreased from $0.86,0.75$, and 0.75 , respectively, in the $0-20 \mathrm{~m}$ stratum to 0.35 , 0.08 , and 0.34 , respectively, in the $20-38 \mathrm{~m}$ stratum (Table 1 and Fig.4B). $\delta^{15} \mathrm{~N}$ values confirmed that in the shallowest stratum pelagic species were able to feed on the benthic pathway. The mean $\delta^{15} \mathrm{~N}$ ratio of $C$. harengus was indeed $1.5 \%$ lower in the $0-20 \mathrm{~m}$ stratum than in the $20-38 \mathrm{~m}$ stratum (Fig.4A), probably because the base of the benthic pathway (defined here by suspension-feeding bivalves; mean $\delta^{15} \mathrm{~N}$ of $8.7 \%$ ) had a lower $\delta^{15} \mathrm{~N}$ than the base of the pelagic pathway (defined by copepods; mean $\delta^{15} \mathrm{~N}$ of $10.3 \%$ ).

Secondly, contrary to small pelagics such as S. pilchardus and C. harengus, pelagic species from sub-group 4.3, such as mackerel Scomber scombrus or horse mackerel Trachurus trachurus, confirmed their pelagic affinity by staying in the pelagic pathway even in the shallow stratum (Fig. 3A and S2) where they either formed a distinct group ( $S$. scombrus) or clustered with large demersal fishes of sub-group 6.2 (T. trachurus). The benthic contribution to their diet varied between 0.1 and 0.2 whatever the depth stratum (Table 1 and Fig.4B).

Thirdly, it is interesting to note that the benthic contribution to the diet of most species closely related to the bottom (flatfishes and rays in group 5 and Gobidae in sub-group 6.1) increased with increasing depth (Table 1 and Fig.4B). This, together with the translation of small pelagics towards the benthic pathway, confirmed that, in shallow waters, both pelagic and benthic carbon sources are accessible to any species whatever its water column position because of physical proximity. In contrast, in deeper areas, physical decoupling is such that species access to carbon sources according to their water column position. For example, in the 0-20m stratum, plaice Pleuronectes platessa and dab Limanda limanda (group 5) lay at the intersection between the pelagic and the benthic trophic pathway (see dotted lines in Fig. 3; benthic contribution to diet of 0.57 and 0.60, respectively; Table 1 and Fig.4B), whereas in the $20-38 \mathrm{~m}$ stratum, they preferentially preyed upon benthic carbon sources (benthic 
1

contribution of 0.77 and 0.81 , respectively; Table 1 and Fig.4B). Another example is thornback ray Raja clavata (group 5), the benthic contribution to its diet increasing constantly with depth (0-20m: 0.62; 20-38m: 0.92; 38-79m: 0.99; Table1 and Fig.4B).

\subsubsection{Continuous gradient approach}

An inshore-offshore gradient in upper consumers ${ }^{\text {ee }} \delta^{15} \mathrm{~N}$ values was evidenced by generalized least squares modelling. The mean of $\delta^{15} \mathrm{~N}$ values decreased significantly with increasing depth (slope $\left.=-0.0109 ; \mathrm{F}_{771}^{1}=7.33, \mathrm{p}=0.0069\right)$ (Fig. 5A). In contrast, their variance increased significantly with depth according to an exponential function ( variance $=1.106 \exp (0.0087$ depth $\left.) ; \chi_{1}^{2}=24.40, \mathrm{p}<0.0001\right)$, so that the observed range of $\delta^{15} \mathrm{~N}$ values was larger offshore. An inshore-offshore seaward gradient was also found in upper consumers ${ }^{\text {ee }}{ }^{13} \mathrm{C}$ values. The mean decreased slightly, but non-significantly, as depth increased (slope $=-0.0003 ; \mathrm{F}_{771}^{1}=0.01, \mathrm{p}=0.9114$ ). However, contrary to $\delta^{15} \mathrm{~N}$, the range of $\delta^{13} \mathrm{C}$ values decreased offshore (Fig. 5B) as evidenced by a significant decrease in variance according to a power function of depth $\left(\right.$ variance $=3.0786$ depth $^{-0.1286} ; \chi_{1}^{2}=6.34, \mathrm{p}=$ $0.0118)$.

Results of the theoretical two-source mixing model showed that the inshore-offshore 481 gradient observed in upper consumers' $\delta^{13} \mathrm{C}$ ratios could be linked to diminishing pelagic-

benthic coupling as depth increases (Fig. 6). More precisely, the decrease in variance of the benthic contribution $\alpha$ to consumers' diet with increasing depth resulted in a unimodal distribution of $\alpha$ values with large variations in the consumer community at shallow depth that turned roughly bimodal with smaller variations as depth increased (Fig. 6A-C). Based on the 486 distribution of the $\delta^{13} \mathrm{C}$ values of benthic and pelagic carbon sources (Fig. 6D), resulting 487 consumers' $\delta^{13} \mathrm{C}$ values had a roughly constant mean (Fig. 6E) and a decreasing variance (Fig. 
$6 \mathrm{~F})$ with increasing depth. This theoretically-predicted gradient in upper consumers' $\delta^{13} \mathrm{C}$ ratios corresponded qualitatively to the pattern observed in our data. This is consistent with the hypothesis that the observed inshore-offshore gradient in upper-consumers' $\delta^{13} \mathrm{C}$ values detected by generalized least squares modelling is related to stronger pelagic-benthic coupling in shallow coastal areas.

\section{Discussion}

Our results revealed that the food web of the EEC forms a continuum of four TLs with trophic groups spread across two trophic pathways relying on pelagic and benthic carbon sources, respectively. Besides this classical global-scale structure for a temperate coastal ecosystem, we found an inshore-offshore gradient in the trophic network structure due to the reorganization of the upper consumers relative to the two trophic pathways. More precisely, the pelagic-benthic coupling was stronger in shallow waters where upper consumers, mostly fishes, could access and use both pelagic and benthic carbon sources irrespective of their water column position preference.

\subsection{Global-scale trophic network structure in the eastern English Channel}

The global-scale structure of the trophic network in the EEC was comparable with that observed in other temperate coastal ecosystems although the taxonomic composition of communities may differ. This suggests that some general principle may apply despite potentially varying forcing factors. In the Bay of Biscay (west coast of France), three trophic 510 groups of primary and secondary consumers, similar to those in the EEC, have been identified 511 on the basis of $\delta^{15} \mathrm{~N}$ and $\delta^{13} \mathrm{C}$ ratios (Le Loc ${ }^{e c}$ et al., 2008): zooplankton plus suprabenthos, 512 benthic suspension feeders, surface-deposit feeders, and a cluster of fishes, cnidarians and 
513 polychaetes. Upper consumers were also organized in three to four trophic groups depending

on their TL and according to their feeding affinity, either pelagic, benthic or omnivores.

Similarly, on the continental shelf of south-eastern Australia, five groups of fishes were identified, roughly comparable with those reported in this study (Davenport and Bax, 2002): 517 piscivorous predators, benthic-feeding sharks and rays, fishes preying on both benthic and 518 pelagic organisms, and two groups of pelagic feeders. This kind of structure was also 519 observed in the Middle Atlantic Bight on the eastern continental shelf of the United States 520 (Woodland and Secor, 2013). Upper consumers are thus organized in similar 521 functional/trophic groups in these ecosystems presenting significant pelagic-benthic coupling.

The existence of a pelagic and a benthic trophic pathway is a general feature in aquatic ecosystems (Davenport and Bax, 2002; Le Loc ${ }^{\text {ech }}$ et al., 2008; Syväranta et al., 2011). Generally, the segregation between the pelagic and the benthic trophic pathway becomes blurred when moving up the food web (higher consumers being at intermediate $\delta^{13} \mathrm{C}$ values), probably due to an increase in foraging area with consumers ${ }^{\text {ee }}$ size that results in more connected food webs as the size, and thus the trophic level, of consumers increases. This inherent structuring of aquatic ecosystems confers stability to their food webs (Rooney et al., 2006). Also, the number of TLs identified at the global scale in the EEC (4) seems to be common in marine food webs (e.g. Davenport and Bax, 2002; Le Loc ${ }^{\text {ech }}$ et al., 2008; Woodland and Secor, 2013). Even if some trophic networks may reach up to eight TLs, the trophic scale of the EEC was indeed coherent with the average food chain length of roughly four TLs found in marine food webs, be it in estuarine, coastal or pelagic systems (Vander Zanden and Fetzer, 2007). It appears therefore, that the global-scale trophic network of the EEC is mostly structured by trophic pathways and carbon sources, as highlighted by the large range of $\delta^{13} \mathrm{C}$ ratios, rather than by TLs. This pattern is expected in continental shelf seas where predators share diverse food resources and where pelagic-benthic coupling is stronger 
538 than in deeper oceanic ecosystems. In contrast, pelagic systems should be strongly structured 539 by TLs due to size-dependent predation. Although TLs were clearly distinct at the base of the food web, they become more unclear higher in the food web (Fig. 2). Upper consumers ${ }^{\text {ee }} \delta^{15} \mathrm{~N}$ ratios suggest that the fish assemblage crosses two TLs, meaning that some fishes are at least 542 partially piscivorous and could be defined as top-predators. The narrow ranges of $\delta^{15} \mathrm{~N}$ and $543 \delta^{13} \mathrm{C}$ values expressed by the five groups of secondary and tertiary consumers indicated that 544 many species share common trophic position and uptake carbon in relatively similar 545 proportions in the benthic and the pelagic trophic pathway. The positioning of organisms 546 along a continuum of trophic levels rather than in discrete ones may be considered as a sign of 547 prevalent omnivory (France et al., 1998), which is in line with the idea that species located 548 high in the food chain tend to become omnivorous, i.e., rely on resources exhibiting a large 549 range of trophic levels (Polis and Strong, 1996). The large size of top-predators promotes 550 their omnivory as they can prey on a larger range of prey sizes spread across the trophic

\subsection{Reorganization of the trophic network structure along an inshore-offshore gradient}

While the mean of upper consumers' $\delta^{15} \mathrm{~N}$ and $\delta^{13} \mathrm{C}$ values remained approximately constant with depth (non-significant change for $\delta^{13} \mathrm{C}$ and significant change with a shallow slope of -0.0109 for $\delta^{15} \mathrm{~N}$ ), we detected of an inshore-offshore gradient in their variance with depth. The variance of upper consumers ${ }^{e e} \delta^{15} \mathrm{~N}$ values increased significantly with increasing depth, notably with rather low values of $\delta^{15} \mathrm{~N}$ (down to 10\%) for consumers located in deep areas, whereas the variance of $\delta^{13} \mathrm{C}$ ratios increased as depth decreased, with $\delta^{13} \mathrm{C}$ values 
563 down to $-22 \%$ for some consumers in shallow areas, a carbon ratio that is usually observed

for primary producers such as phytoplankton (France, 1995). The similarity with the pattern of $\delta^{13} \mathrm{C}$ ratios with depth predicted by our theoretical two-source mixing model suggests that this feature was consistent with the hypothesis of a stronger pelagic-benthic coupling in shallow coastal areas that translates into wider variations of the contribution of pelagic and benthic sources of carbon to upper consumers ${ }^{\text {ee }}$ diet whatever their initial affinity and/or water column position.

In parallel, the discrete approach showed a reorganization of the upper trophic levels 571 of the food web in terms of the carbon sources utilized from coastal to offshore areas. This 572 again can be interpreted as a stronger pelagic-benthic coupling in coastal areas, which resulted 573 in a larger range of $\delta^{13} \mathrm{C}$ values. More precisely, in coastal areas, benthic carbon sources were 574 accessible to pelagic fishes such as S. pilchardus and C. harengus and, reciprocally, pelagic 575 carbon sources were accessible to benthic species such as flatfishes and elasmobranchs. 576 Basically, as depth decreased, diel vertical migrations of zooplankton (Hays et al., 2003) and 577 epibenthic fauna (annelids, decapods and fishes; Vallet and Dauvin 2004; Woodland and 578 Seccor, 2013) in the water column as well as associated vertical migration of pelagic fishes 579 following their prey (Casini et al., 2004) would facilitate the pelagic-benthic coupling. It is 580 interesting to note that this effect of depth on the strength of the pelagic-benthic coupling has 581 a parallel in some deep water systems off the continental slope (e.g. northeast Atlantic deep waters of the Rockall-Porcupine continental margin off northwest UK and Ireland). In these systems, the diel vertical migration of pelagic preys impinges on the benthic boundary layer fauna of the slope during daytime. This allows demersal bentho-pelagic feeders to access 585 pelagic resources between 500 and $1000 \mathrm{~m}$ but not deeper as diel vertical migration is limited 586 to the 0-1000m layer (Mauchline and Gordon, 1991; Trueman et al., 2014). 
Taken together, these results suggest that marine shelf ecosystems such as the EEC 606

can exhibit an inshore-offshore gradient in their trophic network structure underlain by a gradient in pelagic-benthic coupling strength. In coastal areas, the food web relied on a large basis in terms of carbon sources (large range of $\delta^{13} \mathrm{C}$ values) and had a reduced number of TLs (small range of $\delta^{15} \mathrm{~N}$ values) probably due to the fact that predators shared diverse food resources irrespective of their body size or compartment of origin (pelagic or benthic). In contrast, in offshore areas, the trophic network depended mainly on pelagic sources of carbon (reduced range of $\delta^{13} \mathrm{C}$ values) and was more strongly structured by TLs (large range of $\delta^{15} \mathrm{~N}$ values), most likely because of a lower diversity of food resources being accessible. This may also be related to the fact that individuals feed on planktonic resources according to their body size (Blanchard et al. 2009; Woodland and Secor, 2013), since in pelagic size-structured systems smaller preys have a larger per unit biomass production rate (Heckmann et al., 2012).

Adaptive foraging could be hypothesized as the proximal process responsible for the reorganization of the food web along the inshore-offshore gradient. It is the ability of a species to adapt its foraging efforts to variability in its trophic environment, i.e., changes in 602 prey abundance or prey specific composition. Notably, adaptive foraging is expected to favor 603 the use of resources closer to the base of the food web (Heckmann et al., 2012), improve 604 food-web stability (Uchida et al., 2007; Loeuille, 2010; Heckmann et al., 2012), and enhance 605 food-web resilience and resistance against perturbations (Valdovinos et al., 2010), which

could be an important feature in relatively perturbed coastal areas such as those in the EEC (Carpentier et al., 2009). Predator species that adapt their foraging behaviour are able to prey on lower trophic levels, and take advantage of trophic resources directly accessible and 609 optimal without hunting high in the food chain. They focus on the most profitable prey and 610 release unprofitable ones from predation (Heckmann et al., 2012). In coastal areas of the EEC, 611 benthic food resources such as primary consumers are abundant and diversified (Foveau et al., 
2013). The large range of their body sizes, their specific richness and their accessibility due to shallowness may induce an adaptive change in the foraging behavior of some species that would target benthic preys in shallow coastal areas even if they have pelagic affinities. Contrarily, in deep offshore areas, only planktonic resources are available to pelagic upper consumers because of the distance to the seabed.

The case of herring illustrates pretty well the changes observed in $\delta^{15} \mathrm{~N}$ and $\delta^{13} \mathrm{C}$ ratios according to depth. In the intermediate depth stratum (20-38m), this species was located in the pelagic pathway $(\alpha=0.08$; Fig. 4$)$ at a relatively high trophic level $(\mathrm{TL}=3.7$; Fig. 3$)$. In contrast, in the shallow depth stratum $(0-20 \mathrm{~m})$, this species took advantage of both the pelagic and the benthic pathway ( $\alpha=0.75$; Fig. 4$)$, and occupied a lower trophic level (3.2; Fig. 3 and 4). Even if herring does not express an ontogenetic diet shift and is identified as zooplanktivorous during its entire lifespan, it exhibits plasticity in feeding behaviour so that, according to prey availability, accessibility and profitability, it can exploit nektobenthos and zoobenthos in addition to zooplankton (Casini et al., 2004). The low TL and strong contribution of benthic carbon to its diet are thus evidences that this species fed on benthic resources directly accessible in shallow coastal areas. The same type of pattern was observed by Jennings et al. (1997) in heterogeneous Mediterranean reefs environment where they found that a given fish species may present different trophic levels at different sites (deviations of $\sim 2 \%$ in $\delta^{15} \mathrm{~N}$ ) and that the benthic pathway is an important carbon source even for fishes that are known to be pelagic feeders such as Atherinids. For fishes from the North Carolina 632 continental shelf as well, Thomas and Cahoon (1993) found that isotopic ratios varied with 633 location, fishes feeding on food items according to their availability in the environment rather 634 than preying selectively. We hypothesize that many fish species that live in heterogeneous 635 environments such as shelf seas are able to change their trophic position within food webs in response to local conditions, especially food resources availability. This ability of using 
alternative food resources from different trophic levels is defined by Darnell (1961) as one of the main processes improving populations ${ }^{\text {ee }}$ stability in complex natural communities and plasticity in feeding strategy would allow fishes to respond to local variations in food availability.

\subsection{Strength and limitations of the study}

This study provides one of the largest, if not the largest, sampling plan of food web structure in temperate coastal ecosystems where the implications of spatial scale and variations along an environmental gradient are treated explicitly. A partly similar study by Woodland and Secor (2013) extended over roughly $360 \mathrm{~km}^{2}$ whereas the present study covers nearly $35000 \mathrm{~km}^{2}$. At such scale, it is of course difficult to balance sampling effort across space and species, especially when species diversity is high. Combined with the fact that most of our samples were collected by bottom trawling, it resulted that small epibentic fauna was under-represented in and that infauna was almost absent from our sampling. However, given that we sampled a high diversity of organisms in the EEC, from epibenthic macrofauna, to phytoplankton and zooplankton, to large predatory fishes, we are quite confident that our findings are representative of the trophic structuring of macro-organisms living on the seabed and in the water column. Furthermore, the fine taxonomic resolution of our study, i.e. at the species level in most cases, and the correction for spatial variation in stable isotopic ratios of the trophic baseline, which is rare at such spatial scale (but see Jennings and Warr, 2003a,b or 657 Barnes et al., 2009), ensures unbiased estimates of TLs and contributions of carbon sources. 658 This may not be the case in food web studies with coarser taxonomic resolution (Hall and 659 Raffaelli, 1993) or neglecting spatial variation in baseline isotopic ratios. 

669

2005; Barnes et al., 2009) and thus should provide a picture of the food web that holds at a seasonal timescale at least. In this context, organismsee movements, notably in highly migratory fishes, can be a source of potential error and we are aware that baseline corrections for these species could be debatable. Fish movements can be of three kinds: movements 666 within the home range, migrations due to ontogenetic shifts, and spawning migrations 667 (Pittman and McAlpine, 2003). Regarding home range and foraging area, they usually scale 668 with body size in marine fishes but, although fishes are known as mobile species, they do not exceed the order of $100 \mathrm{~km}^{2}$ (e.g. for cod) and are linked to species ${ }^{\mathrm{ee}}$ habitat (Pittman and Mac Alpine, 2003). Given that, first, we considered a spatial scale that is roughly 350 times higher than the home range of the biggest fishes sampled and, second, we focused on changes in food web structure with depth, a very good proxy of habitat in continental shelf seas such as the EEC (Vaz et al, 2007; Martin et al., 2010), we do not expect fish movement within their home range (i.e. excluding migrations) to affect our results strongly. Regarding ontogenic migration, given that our sampling scheme avoided nursery areas where are located juvenile fish and targeted mostly adult fishes, our results on the inshore-offshore gradient in the pelagic-benthic coupling should also not be influenced strongly by migrations related to the processes of ontogenetic shifts. With respect to spawning migration, the reproductive season of most fish species in the EEC spread from winter to summer (Carpentier et al., 2009) so that spawning migrations should not affect deeply the composition of the fish assemblage as we observed it in October.

Of course, even within a species ${ }^{e c}$ home range, individuals may feed at a given location and be captured at another one. Likewise, the presence in our samples of non-resident individuals originating from outside the EEC because of any type of migration cannot be excluded. In both cases, the correction for spatial variation in baseline isotopic ratios may be partly wrong. The maximum amplitude of variation in baseline ratios is roughly of $1.5 \%$ for 
687 both $\delta^{15} \mathrm{~N}$ and $\delta^{13} \mathrm{C}$ be it within the eastern English Channel (home range; Fig. S1) or between the EEC and the main areas of origin of potential migrating non-residents, namely the western English Channel and the south North Sea (Jennings and Warr, 2003; Barnes et al. 2009). This would generate a maximum bias of roughly \pm 0.4 for TLs and \pm 0.3 for the contribution of benthic carbon to consumers ${ }^{\text {e }}$ diet. As non-residents are most likely large predatory fish, this may contribute to the blurring of the food web at high trophic levels. However, because bias will be most often smaller than these maximum values and because it should be distributed randomly across individuals, we believe that fish movement within their home range and fish migration should not affect our qualitative results. Most importantly, the fact remains that despite the potential noise generated by migrations and movements we found significant variation in the structure of the EEC food web along the inshore-offshore gradient.

699 Conclusion

700 Spatial variability along environmental gradients has been rarely considered in studies that 701 have aimed at describing food web structure (but see Woodland and Secor, 2013). The 702 structure of the food web from the EEC, characterized by two main trophic pathways and four 703 trophic levels, seems relatively conventional for comparable marine ecosystems. The main 704 originality, which we believe could be generalized to most continental shelf seas, lies in the 705 particular depth structure of the EEC that confers specific properties to its food web, notably an inshore-offshore gradient in its structure. More specifically our results highlighted that the pelagic-benthic coupling is stronger in shallow coastal areas due to some upper consumers that exhibit foraging plasticity and can extend their trophic niche to various sources of carbon 709 presumably according to the availability of prey. Given that the observed structure of food 710 webs can be highly variable depending on the resolution considered, our results suggest that 
accounting for spatial variability (from local to regional scale as recommended by Ings et al.,

2009) is crucial to better understand trophic processes at play.

\section{Acknowledgements}

This work was part-funded by the INTERREG IV A France (Channel) - England cross-border

European cooperation programme, co-financed by the European Regional Development Fund as part of the CHannel integrated Approach for marine Resource Management (CHARM) Phase 3 project. Authors would like to thank the SOMLIT team from UMR 8187 LOG at Wimereux (France, http://somlit.epoc.u-bordeaux1.fr/fr/) and especially (E. Lecuyer and E. Breton) for providing POM isotope ratios. Finally, authors would like to thank Peter Magee for professional English editing (www.englisheditor.webs.com).

\section{References}

Albouy, C., Mouillot, D., Rocklin, D., Culioli, J.M., Le Locen, F., 2010. Simulation of the combined effects of artisanal and recreational fisheries on a Mediterranean MPA ecosystem using a trophic model. Marine Ecology Progress Series 412, 207-221.

Barnes, C., Jennings, S., Barry, J.T., 2009. Environmental correlates of large-scale spatial variation in the $\delta^{13} \mathrm{C}$ of marine animals. Estuarine, Coastal and Shelf Science 81, 368374.

Barnes, C., Maxwell, D., Reuman, D.C., Jennings, S., 2010. Global patterns in predator-prey size relationships reveal size dependency of trophic transfer efficiency. Ecology 91, $222-232$

Berlow, E.L., 1999. Strong effects of weak interactions in ecological communities. Nature $398,330-334$. 
735 Blanchard, J.L., Jennings, S., Law, R., Castle, M.D., McCloghrie, P., Rochet, M.-J., Benoît,

E., 2009. How does abundance scale with body size in coupled size-structured food webs? Journal of Animal Ecology 78, 270-280.

Blanchard, J.L., Law, R., Castle, M.D., Jennings, S., 2011. Coupled energy pathways and the resilience of size-structured food webs. Theoretical Ecology 4, 289-300.

Borcard, D., Gillet, F., Legendre, P., 2011. Numerical Ecology with R. UseR! Series. Springer, New York, USA.

Brose, U., Berlow, E.L., Martinez, N.D., 2005. Scaling up keystone effects from simple to complex ecological networks. Ecology Letters 8, 1317-1325.

Carpentier, A., Martin, C.S., Vaz, S., 2009. Channel habitat atlas for marine resource management, final report. INTERREG 3a Programme, IFREMER, France. Available: http://archimer.ifremer.fr/doc/2009/rapport-7377.pdf.

Casini, M., Cardinale, M., Arrhenius, F., 2004. Feeding preferences of herring (Clupea harengus) and sprat (Sprattus sprattus) in the southern Baltic Sea. ICES Journal of Marine Science 61, 1267-1273.

Chouvelon, T., Spitz, J., Caurant, F., Méndez-Fernandez, P., Chappuis, A., Laugier, F., Le Goff, E., Bustamante, P., 2012. Revisiting the use of $\delta^{15} \mathrm{~N}$ in meso-scale studies of marine food webs by considering spatio-temporal variations in stable isotopic signatures. The case of an open ecosystem: the Bay of Biscay (North-East Atlantic). Progress in Oceanography 101, 95-102.

Cohen, J.E., Pimm, S.L., Yodzis, P., Saldaña, J., 1993. Body sizes of animal predators and animal prey in food webs. Journal of Animal Ecology 62, 67-78.

Darnaude, A.M., Salen-Picard, C., Polunin, N.V.C., Harmelin-Vivien, M.L., 2004. Trophodynamic linkage between river runoff and coastal fishery yield elucidated by stable isotope data in the Gulf of Lions (NW Mediterranean). Oecologia 138, 325-332. 
760 Darnell, R.M., 1961. Trophic spectrum of an estuarine community, based on studies of Lake

Davenport, S.R., Bax, N.J., 2002. A trophic study of a marine ecosystem off southeastern Australia using stable isotopes of carbon and nitrogen. Canadian Journal of Fisheries and Aquatic Sciences 59, 514-530.

Delpech, J.-P., Mahe, K., Mehault, S., Rostiaux, E., Biais, G., Coppin, F., Vaz, S., 2007. Fisheries ressources assesment with french scientific surveys, "Eastern Channel" and "Loire-Gironde" areas. Ifremer, Direction des Ressources Vivantes, Département des Ressources Halieutiques, http://archimer.ifremer.fr/doc/2007/rapport-6642.pdf.

De Niro, M.J., Epstein, S., 1978. Influence of diet on distribution of carbon isotopes in animals. Geochimica et Cosmochimica Acta 42, 495-506.

Dézerald, O., Leroy, C., Corbara, B., Carrias, J.-F., Pélozuelo, L., Dejean, A., Céréghino, R., 2013. Food-web structure in relation to environmental gradients and predator-prey ratios in tank-bromeliad ecosystems. PloS one 8, e71735.

Diggle, P.J., Ribeiro Jr., P.J., 2007. Model-based geostatistics. Springer, New York, USA.

Dunne, J.A., 2006. The Network Structure of Food Webs. In: Pascual, M., Dunne, J.A. (Eds.), Ecological networks: linking structure to dynamics in food webs. Oxford Univ. Press, New York, pp. 27-86.

Foveau, A., Desroy, N., Dauvin, J.C., Dewarumez, J.M., 2013. Distribution patterns in the benthic diversity of the eastern English Channel. Marine Ecology Progress Series 479, 115-126.

France, R., 1995. Carbon-13 enrichment in benthic compared to planktonic algae: foodweb implications. Marine Ecology Progress Series 124, 307-312.

France, R., Chandler, M., Peters, R., 1998. Mapping trophic continua of benthic foodwebs: body-size- $\delta^{15} \mathrm{~N}$ relationships. Marine Ecology Progress Series 174, 301-306. 
Hall, S.J., Raffaelli, D.G., 1993. Food webs: theory and reality. Advances in Ecological Research 24, 187-239.

Hays, G.C., 2003. A review of the adaptative significance and ecosystem consequences of zooplankton diel vertical migrations. Hydrobiologia 503, 163-170.

Heckmann, L., Drossel, B., Brose, U., Guill, C., 2012. Interactive effects of body-size structure and adaptive foraging on food-web stability. Ecology Letters 15, 243-250.

Ings, T.C., Montoya, J.M., Bascompte, J., Blüthgen, N., Brown, L., Dormann, C.F., Edwards, F., Figueroa, D., Jacob, U., Jones, J.I., Lauridsen, R.B., Ledger, M.E., Lewis, H.M., Olesen, J.M., van Veen, F.J.F., Warren, P.H., Woodward, G., 2009. Ecological networks - beyond food webs. Journal of Animal Ecology 78, 253-269.

Jennings, S., Warr, K.J., 2003a. Environmental correlates of large-scale spatial variation in the $\delta^{15} \mathrm{~N}$ of marine animals. Marine Biology 142, 1131-1140.

Jennings, S., Warr, K.J., 2003b. Smaller predator-prey body size ratios in longer food chains. Proceedings of the Royal Society B 270, 1413-1417.

Jennings, S., Reñones, O., Morales-Nin, B., Polunin, N.V.C., Moranta, J., Coll, J., 1997. Spatial variation in the ${ }^{15} \mathrm{~N}$ and ${ }^{13} \mathrm{C}$ stable isotope composition of plants, invertebrates and fishes on Mediterranean reefs: implications for the study of trophic pathways. Marine Ecology Progress Series 146, 109-116.

Le Loc ${ }^{c e}$, F., Hily, C., Grall, J., 2008. Benthic community and food web structure on the continental shelf of the Bay of Biscay (North Eastern Atlantic) revealed by stable isotopes analysis. Journal of Marine Systems 72, 17-34.

Loeuille, N., 2010. Consequences of adaptive foraging in diverse communities. Functional Ecology 24, 18-27. 
Logan, J.M., Jardine, T.D., Miller, T.J., Bunn, S.E., Cunjak, R.A., Lutcavage, M.E., 2008. Lipid corrections in carbon and nitrogen stable isotope analyses: comparison of chemical extraction and modelling methods. Journal of Animal Ecology 77, 838-846.

Lorrain, A., Savoye, N., Chauvaud, L., Paulet, Y.M., Naulet, N., 2003. Decarbonation and preservation method for the analysis of organic $\mathrm{C}$ and $\mathrm{N}$ contents and stable isotope ratios of low-carbonated suspended particulate material. Analytica Chimica Acta 491, $125-133$

Martin, C.S., Meaden, G.J., Vaz, S., Dupuis, L., Lauria, V., Ernande, B., Dauvin, J.-C., Spilmont, N, Dewarumez, J.-M., Foveau, A., Garcia, C., Carpentier, A., 2010. Chapter 3. Channel Habitat Atlas for Marine Resource Management - an aid to managing a resource-stressed marine area. In Ocean globe (ed. Joe Breman). ESRI Press Academic, Redlands, California, US.

Mauchline, J., Gordon, J.D.M., 1991. Oceanic pelagic prey of benthopelagic fish in the benthic boundary layer of a marginal oceanic region. Marine Ecology Progress Series $74,109-115$

Maxwell, T.A.D., Jennings, S., 2006. Predicting abundance-body size relationships in functional and taxonomic subsets of food webs. Oecologia 150, 282-290.

Minagawa, M., Wada, E., 1984. Stepwise enrichment of ${ }^{15} \mathrm{~N}$ along food chains: further evidence and the relation between ${ }^{15} \mathrm{~N}$ and animal age. Geochimica et Cosmochimica Acta 48, 1135-1140.

828 Paine, R.T., 1969. A note on trophic complexity and community stability. The American Naturalist 103, 91-93.

Phillips, D.L., Gregg, J.W., 2001. Uncertainty in source partitioning using stable isotopes. Oecologia 127, 171-179. 
832 Pinheiro, J.C., Bates, D.M., 2004. Mixed effect models in S and S-Plus. Springer, New York,

Pinheiro, J.C., Bates, D.M., DebRoy, S., Sarkar, D. and the R Development Core Team, 2013. nlme: Linear and Nonlinear Mixed Effects Models. R package version 3.1-108.

Pinnegar, J.K., Polunin, N.V.C., 1999. Differential fractionation of delta C-13 and delta N-15 among fish tissues: implications for the study of trophic interactions. Functional Ecology 13, 225-231.

Pittman, S.J., McAlpine, C.A., 2003. Movements of marine fish and decapod crustaceans: process, theory and application. Advances in Marine Biology 44, 205-293.

Polis, G.A., Strong, D.R., 1996. Food web complexity and community dynamics. The American Naturalist 147, 813-846.

Post, D.M., 2002. Using stable isotopes to estimate trophic position: Models, methods, and assumptions. Ecology 83, 703-718.

Post, D.M., Layman, C.A., Arrington, D.A., Takimoto, G., Quattrochi, J., Montaña, C.G., 2007. Getting to the fat of the matter: models, methods and assumptions for dealing with lipids in stable isotope analyses. Oecologia 152, 179-189.

R Development Core Team, 2012. R: A language and environment for statistical computing. R Foundation for Statistical Computing, Vienna, Austria. ISBN 3-900051-07-0, http://www.R-project.org/.

Revill, A.T., Young, J.W., Lansdell, M., 2009. Stable isotopic evidence for trophic groupings and bio-regionalization of predators and their prey in oceanic waters off eastern Australia. Marine Biology 156, 1241-1253.

Ribeiro Jr, P.J., Diggle, P.J., 2001. geoR: a package for geostatistical analysis. R-NEWS 1, $15-18$. 
Rodríguez-Graña, L., Calliari, D., Conde, D., Sellanes, J., Urrutia, R., 2008. Food web of a SW Atlantic shallow coastal lagoon: spatial environmental variability does not impose substantial changes in the trophic structure. Marine Ecology Progress Series 362, 69-83.

Rooney, N., McCann, K., Gellner, G., Moore, J.C., 2006. Structural asymmetry and the stability of diverse food webs. Nature 442, 265-269.

Rooney, N., McCann, K.S., 2012. Integrating food web diversity, structure and stability. Trends in Ecology \& Evolution 27, 40-46.

Sholto-Douglas, A.D., Field, J.G., James, A.G., van der Merwe, N.J., 1991. ${ }^{13} \mathrm{C} /{ }^{12} \mathrm{C}$ and ${ }^{15} \mathrm{~N} /{ }^{14} \mathrm{~N}$ isotope ratios in the Southern Benguela Ecosystem: indicators of food web relationships among different size-classes of plankton and pelagic fish; differences between fish muscle and bone collagen tissues. Marine Ecology Progress Series 78, 2331.

Sweeting, C.J., Jennings, S., Polunin, N.V.C., 2005. Variance in isotopic signatures as a descriptor of tissue turnover and degree of omnivory. Functional Ecology 19, 777-784.

Sweeting, C.J., Polunin, N.V.C., Jennings, S., 2006. Effects of chemical lipid extraction and arithmetic lipid correction on stable isotope ratios of fish tissues. Rapid Communications in Mass Spectrometry 20, 595-601.

Syväranta, J., Högmander, P., Keskinen, T., Karjalainen, J., Jones, R.I., 2011. Altered energy flow pathways in a lake ecosystem following manipulation of fish community structure. Aquatic Sciences 73, 79-89.

Therneau, T.M., Atkinson, B., Ripley, B., Oksanen, J., De'ath, G., 2013. mvpart: Multivariate partitioning. R package version 1.6-1. http://CRAN.R-project.org/package=mvpart. 878 Thomas, C.J., Cahoon, L.B., 1993. Stable isotope analyses differentiate between different trophic pathways supporting rocky-reef fishes. Marine Ecology Progress Series 95, 1924. 
Tranter, D.J., Smith, P.E., 1968. Filtration performance. In: Tranter, D.J., Fraser, J.H. (Eds.), Zooplankton sampling: review papers of the proceedings of the symposium on the hydrodynamics of zooplankton sampling. Monographs on Oceanographic Methodology, 2. Unesco Press, Paris, pp. 27-56.

Trueman, C.N., Johnston, G., OHea, B., MacKenzie, K.M., 2014. Trophic interactions of fish communities at midwater depths enhance long-term carbon storage and benthic production on continental slopes. Proceedings of the Royal Society B 281, 20140669.

Uchida, S., Drossel, B., Brose, U., 2007. The structure of food webs with adaptive behaviour. Ecological Modelling 206, 263-276.

Valdovinos, F.S., Ramos-Jiliberto, R., Garay-Narváez, L., Urbani, P., Dunne, J.A., 2010. Consequences of adaptive behaviour for the structure and dynamics of food webs. Ecology Letters 13, 1546-1559.

Vallet, C., Dauvin, J-C., 2004. Spatio-temporal changes of the near-bottom mesozooplankton from the English Channel. Journal of the Marine Biological Association of the U. K. 84, $539-546$.

Vander Zanden, M. J., Fetzer, W.W., 2007. Global patterns of aquatic food chain length. Oikos 116, 1378-1388.

Vaz, S., Carpentier, A., Coppin, F., 2007. Eastern English Channel fish assemblages: measuring the structuring effects of habitats on distinct sub-communities. ICES Journal of Marine Science 64, 271-287.

Vizzini, S., Mazzola, A., 2009. Stable isotopes and trophic positions of littoral fishes from a Mediterranean marine protected area. Environmental Biology of Fishes 84, 13-25.

Wada, E., Mizutani, H., Minagawa, M., 1991. The use of stable isotopes for food web analysis. Critical Reviews in Food Science and Nutrition 30, 361-371. 
905 Ward Jr, J.H., 1963. Hierarchical grouping to optimize an objective function. Journal of the

1 6 American Statistical Association 58, 236-244.

Woodland, R.J., Secor, D.H., 2013. Benthic-pelagic coupling in a temperate inner continental shelf fish assemblage. Limnology and Oceanography 58,966-976.

Worm, B., Duffy, J.E., 2003. Biodiversity, productivity and stability in real food webs. TRENDS in Ecology and Evolution 18, 628-632.

Zuur, A.F., Ieno, E.N., Walker, N.J., Saveliev, A.A., Smith, G.M., 2009. Mixed effects models and extensions in ecology with R. Springer, New York, USA. 
Figure and table captions

Fig. 1 Map of the eastern English Channel (EEC) presenting the three depth strata (shades of grey) used for the discrete gradient approach and the geographical position of the sampling sites (filled circles).

Fig. 2 Mean $\delta^{15} \mathrm{~N}$ and $\delta^{13} \mathrm{C}$ values for all the studied taxa. Circles (Part1) correspond to the results of hierarchical cluster analysis (Part2). (in color on the Web and in black-and-white in print)

Fig. 3 Mean $\delta^{15} \mathrm{~N}$ and $\delta^{13} \mathrm{C}$ values for all the studied taxa in $1^{\text {st }}$ depth stratum $(\mathrm{A}), 2^{\text {nd }}$ depth stratum (B-), and $3^{\text {rd }}$ depth stratum (C-). Circles correspond to the results of hierarchical cluster analysis (Appendix A). Correspondence for colors is the same as in Fig.2. (in color on the Web and in black-and-white in print)

Fig. 4 Trophic level and contribution of benthic carbon to diet for secondary and tertiary consumers in the 3 depth strata. A. Trophic level. B. Contribution of benthic carbon to diet. Dots are average values for $0-20 \mathrm{~m}$ (black), 20-38m (gray) and 38-79m (white) stratum and surrounding black lines denote associated standard errors. Species were ordered according to the contribution of benthic carbon to their diet in the $0-20 \mathrm{~m}$ stratum.

Fig. 5 Relationships between depth and isotopic ratios for secondary and tertiary consumers. A- $\delta^{15} \mathrm{~N}$ and $\mathrm{B}-\delta^{13} \mathrm{C}$. Quantile regressions (0.5: solid line; 0.05 and 0.95: dotted lines) are shown. The boxes represent the interquartile range, the line across is the median value, and the whiskers extend to the most extreme data points which are less than 1.5 times the length of the interquartile range The white points show outliers.

Fig. 6 Theoretical inshore-offshore gradient in the $\delta^{13} \mathrm{C}$ ratio of upper consumers resulting from diminishing coupling of the benthic and the pelagic pathway as depth increases. A, B and C: Distribution of the proportion of benthic source in consumers diet at increasing depth: 10, 40 and $70 \mathrm{~m}$. D. Distribution of the $\delta^{13} \mathrm{C}$ ratio of the benthic and the pelagic source. E. 
939 Resulting inshore-offshore gradient in the mean $\delta^{13} \mathrm{C}$ ratio in consumers. F. Resulting inshore-

offshore gradient in the variance of the $\delta^{13} \mathrm{C}$ ratio in consumers.

Table 1 Names of all the studied species, zones of sampling, number of individuals (n), mean $\delta^{13} \mathrm{C}$ and $\delta^{15} \mathrm{~N}( \pm \mathrm{SD})$, estimated trophic level (TL, $\delta^{15} \mathrm{~N}_{\text {base }}=$ Aequipecten opercularis $)$ and benthic contribution to fish diet $( \pm \mathrm{SE})$. Species were considered in zones when $n>3$, otherwise, individuals were included in the community.

Supplementary material

Fig.S1. Maps of the isotopic ratios of the trophic baseline A. opercularis predicted by kriging from published data. A- $\delta^{15} \mathrm{~N}$ and $\mathrm{B}-\delta^{13} \mathrm{C}$. Plus signs correspond to sampling sites of this study whereas crosses correspond to sampling sites of the data published by Jennings and Warr (2003) and Barnes et al. (2009). Continuous lines are isolines of isotopic ratios.

Fig.S2. Hierarchical clustering for the three depth strata. A- $1^{\text {st }}$ depth stratum, B- $2^{\text {nd }}$ depth stratum, C- $3^{\text {rd }}$ depth stratum.

\section{stratum, C- 3 depth stratum.}




\section{ACCEPTED MANUSCRIPT}

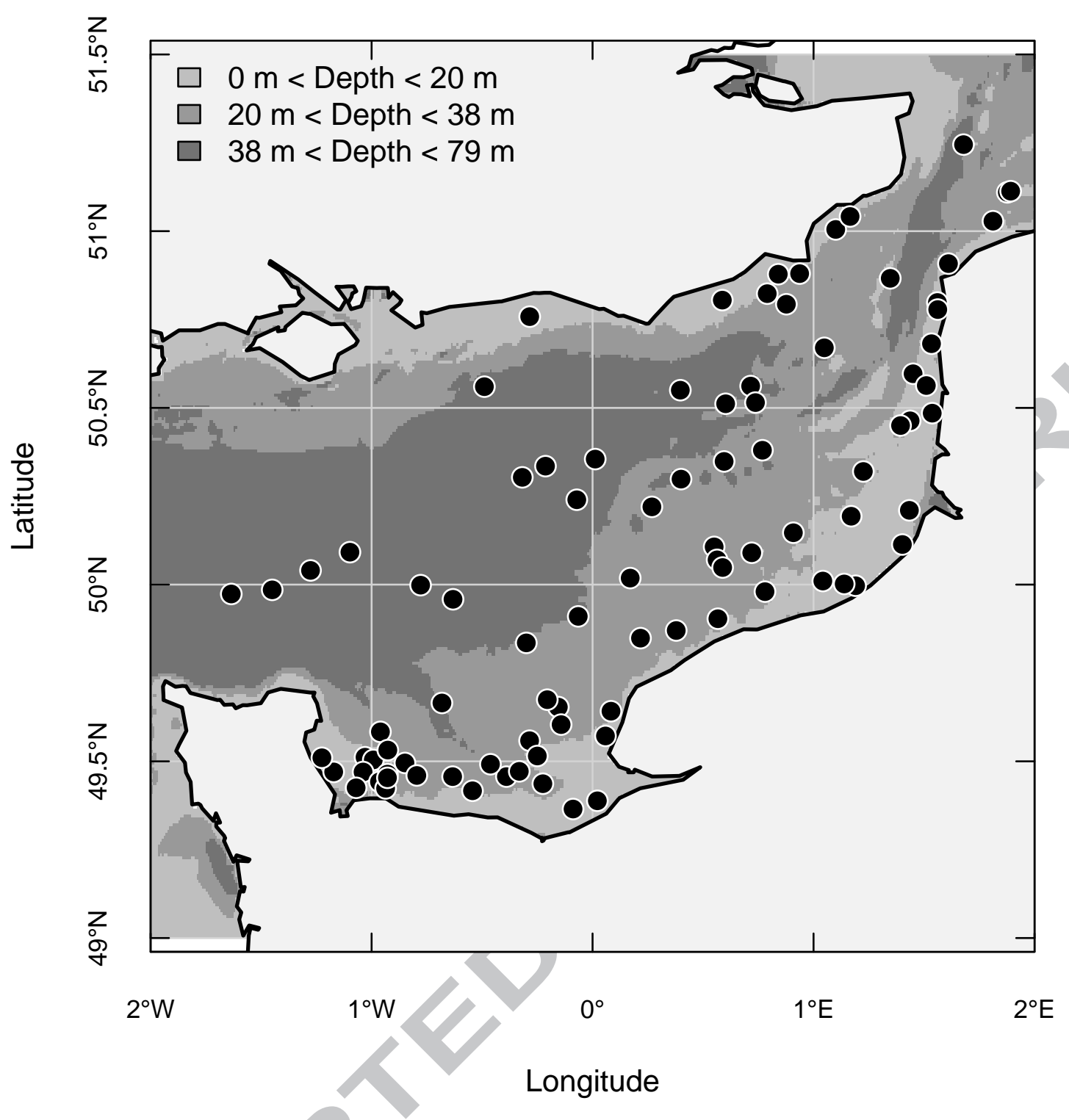




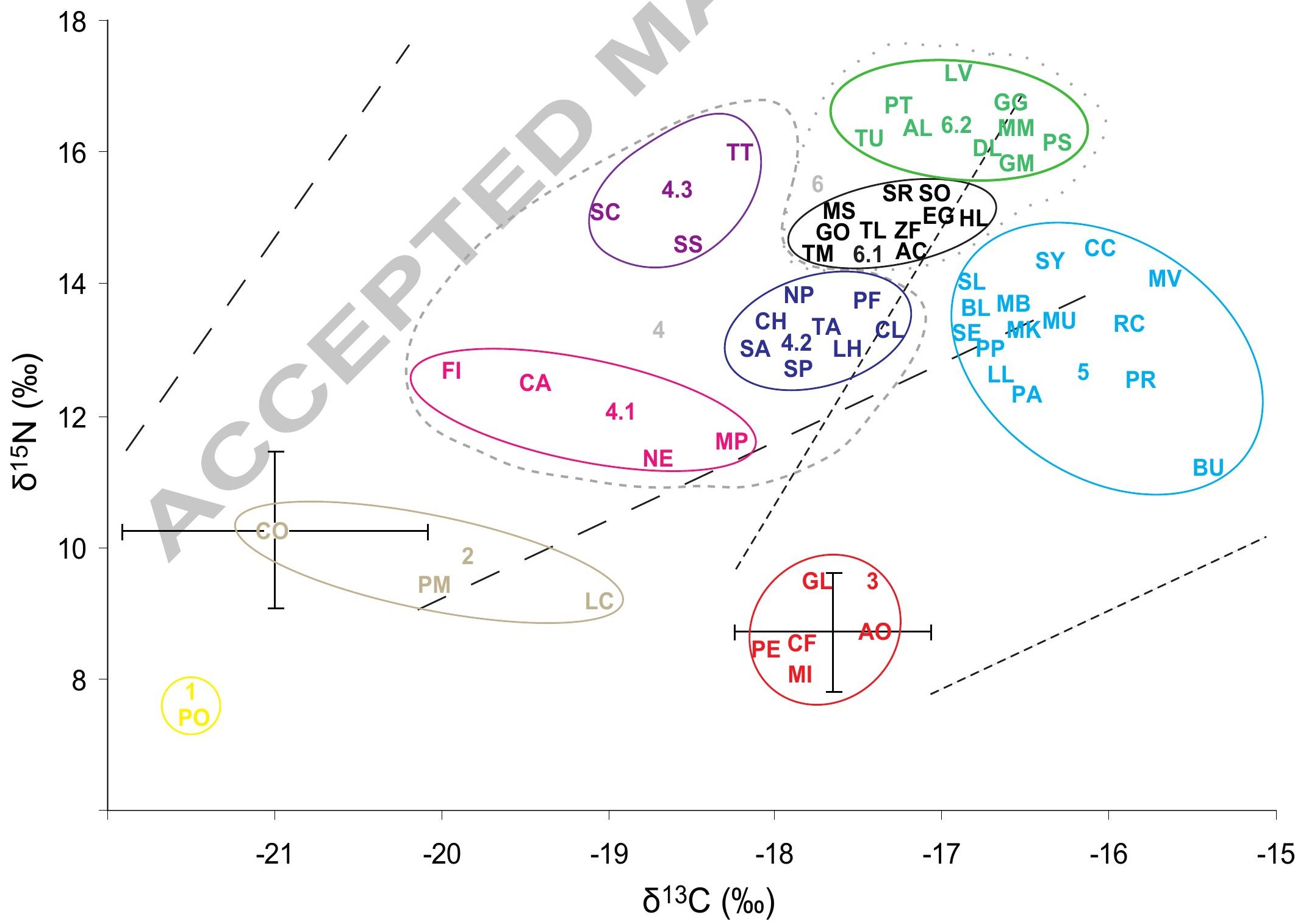




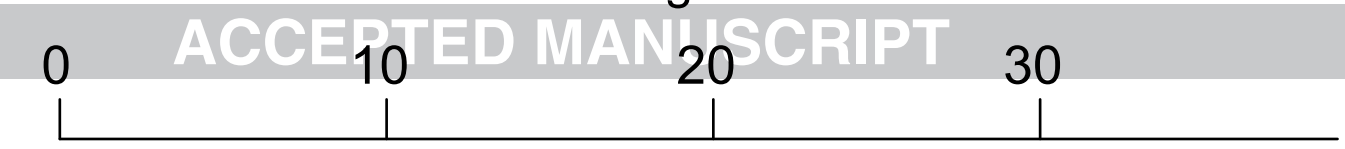

POM PO

Psammechinus miliaris PM Laevicardium crassum LC Glycymeris glycymeris GL

Pecten maximus $\mathrm{PE}$ Mimachlamys varia $\mathrm{MI}$ Crepidula fornicata CF Aequipecten opercularis AO

Buccinum undatum BU

Processa sp. PR

Paguroidae PA

Mustelus sp. MU

Pleuronectes platessa PP

Scyliorhinus stellaris SE

Buglossidium luteum BL

Microstomus kitt MK

Limanda limanda LL

Solea solea SL

Maja brachydactyla MB

Raja clavata RC

Microchirus variegatus MV

Scyliorhinus canicula SY

Crangon crangon $\mathrm{CC}$

Loligo vulgaris LV

Psetta maxima PT

Alloteuthis sp. AL

Chelidonichthys lucerna TU

Dicentrarchus labrax DL

Merlangius merlangus MM

Galeorhinus galeus GG

Palaemon serratus PS

Gadus morhua GM

Scophthalmus rhombus SR

Aspitrigla cuculus AC

Hyperoplus lanceolatus $\mathrm{HL}$

Sepia officinalis SO

Eutrigla gurnardus EG Zeus faber ZF

Trisopterus luscus TL

Mullus surmuletus MS

Gobiidae GO

Trisopterus minutus TM

Scomber scombrus SS

Spondyliosoma cantharus SC

Trachurus trachurus TT

Necora puber NP

Platichthys flesus PF

Trigloporus lastowiza TA -7

Sprattus sprattus SA

Callionymus lyra CL

Liocarcinus holsatus LH

Sardina pilchardus SP

Clupea harengus $\mathrm{CH}$

Micromesistius poutassou MP

Nereis sp. NE

Chaetognaths CA

Fish larvae $\mathrm{FI}$ 

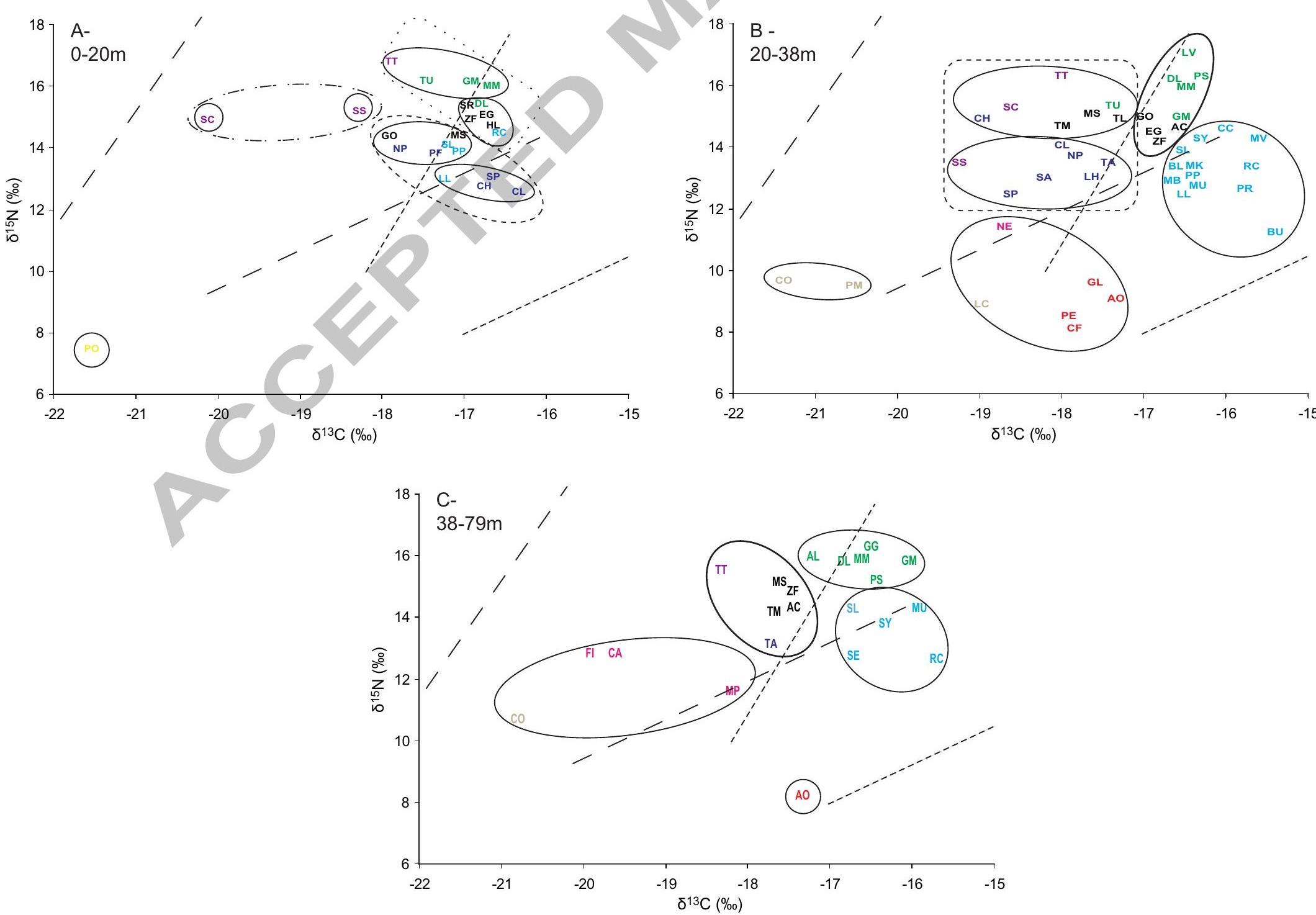


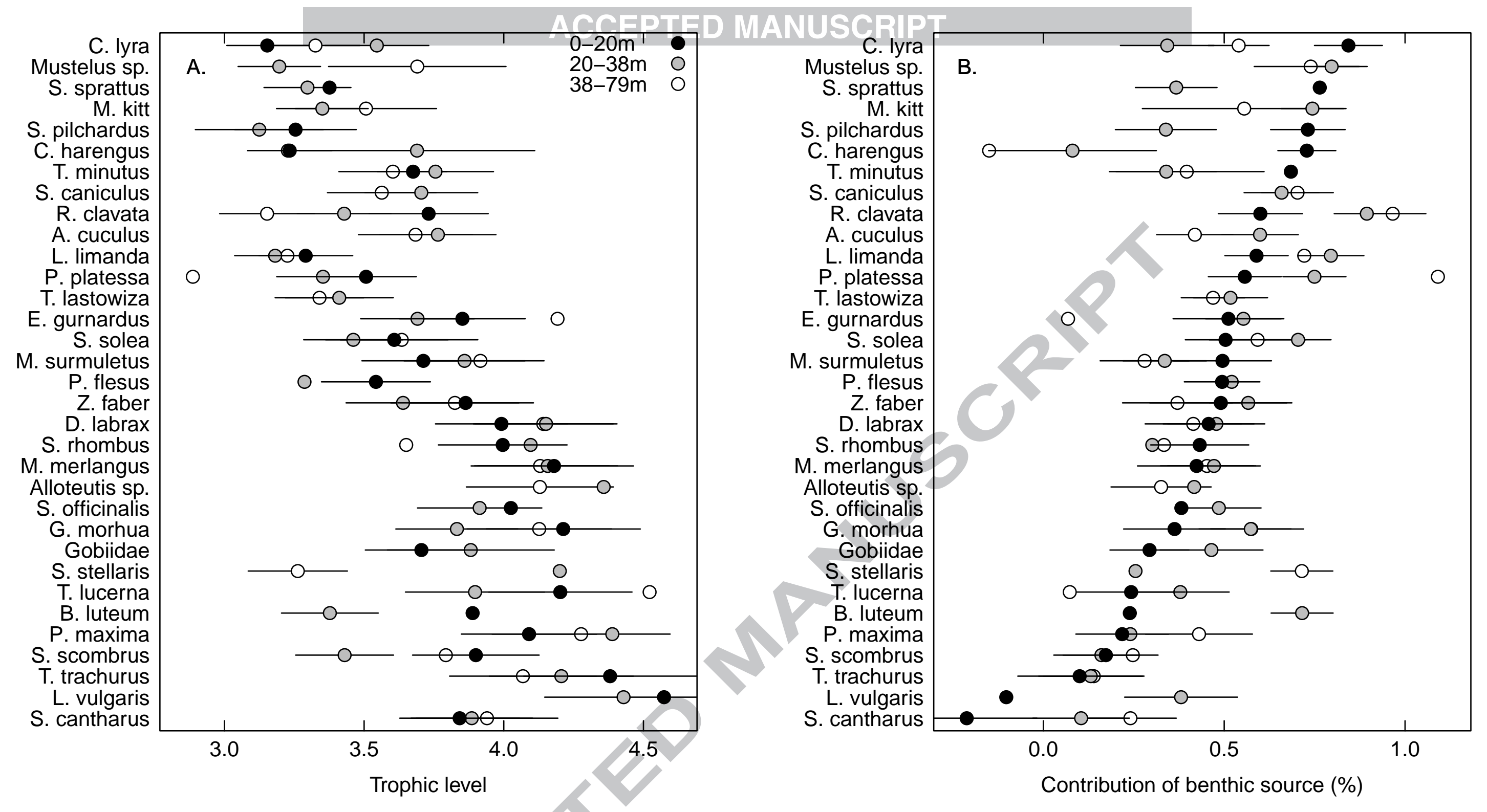



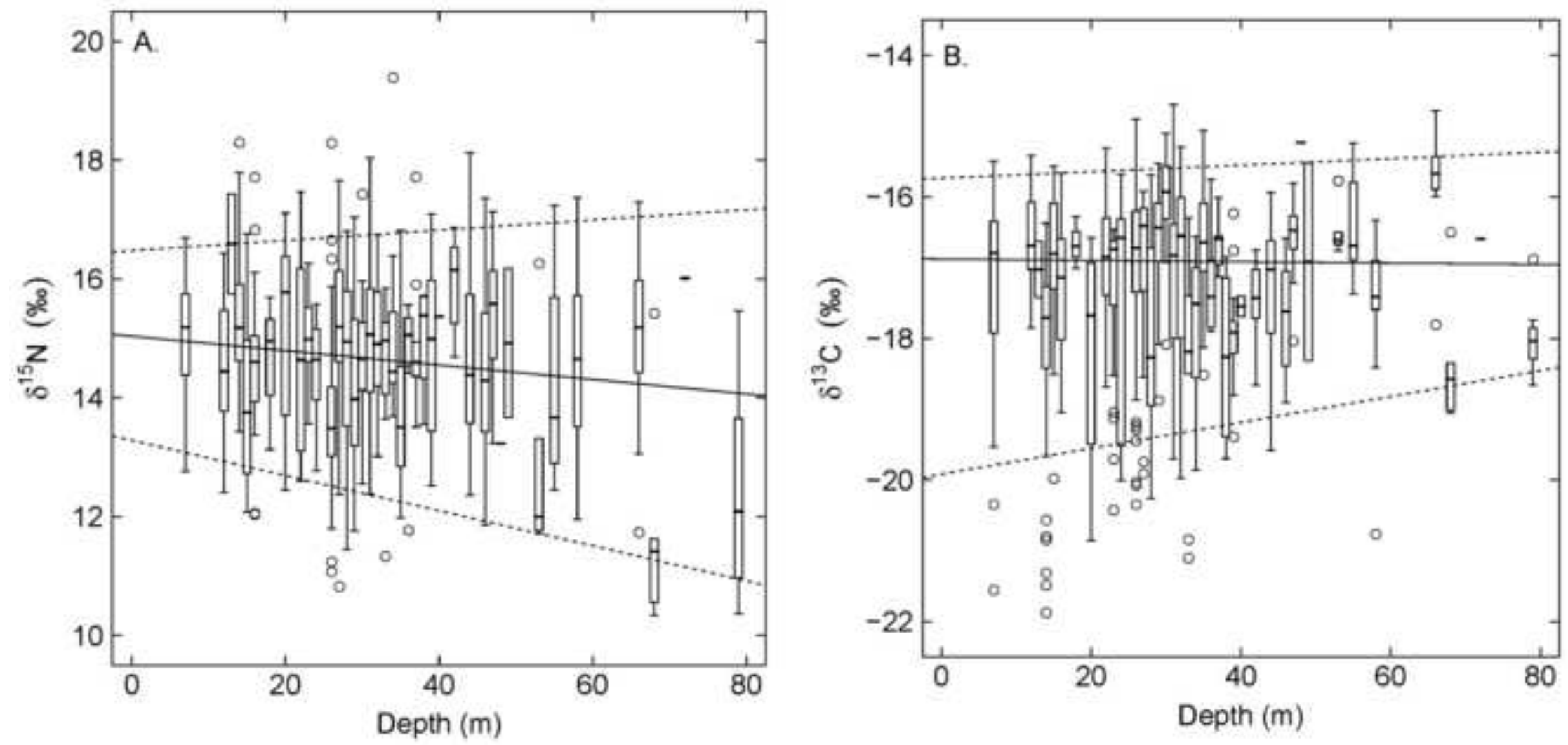
A. $10 \mathrm{~m}$ depth

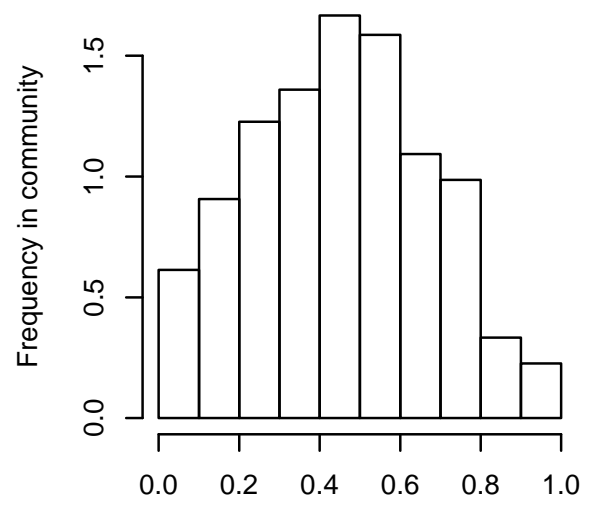

Proportion $\alpha_{C}$ of benthic sources in diet

D. Distribution of $\delta^{13} \mathrm{C}$ values in sources

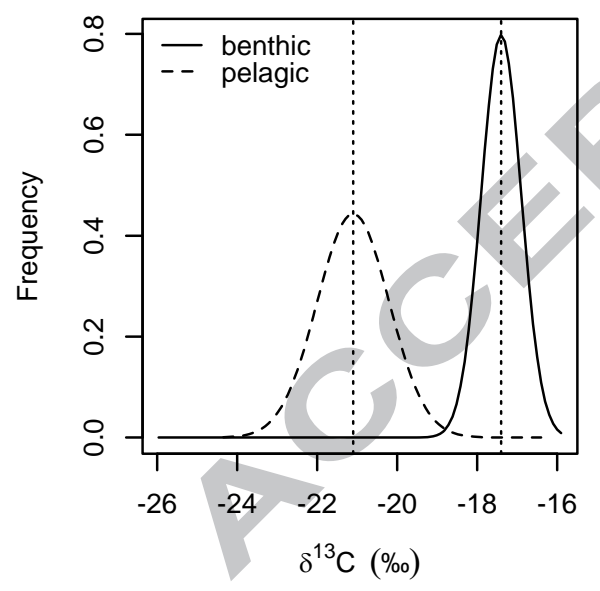

B. $40 \mathrm{~m}$ depth

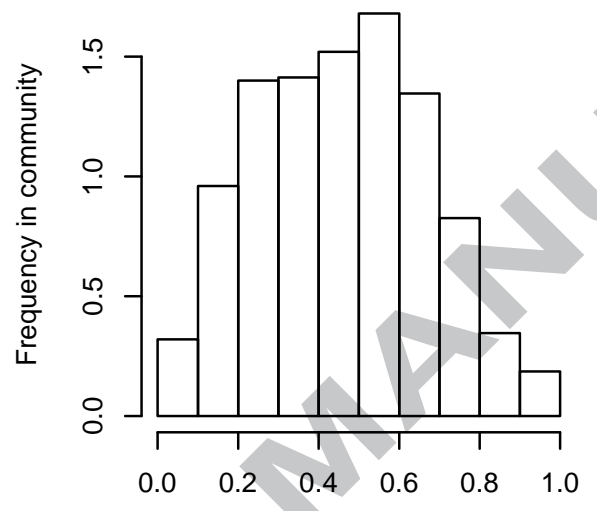

Proportion $\alpha_{C}$ of benthic sources in diet

E. Gradient of $\delta^{13} \mathrm{C}$ in consummers

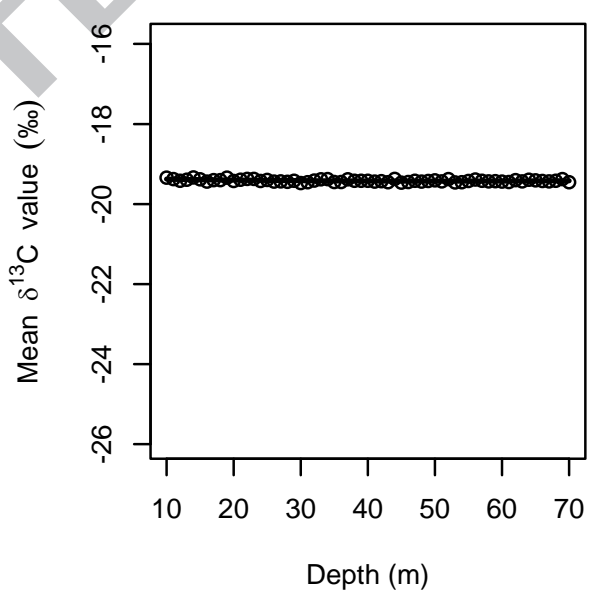

C. $70 \mathrm{~m}$ depth

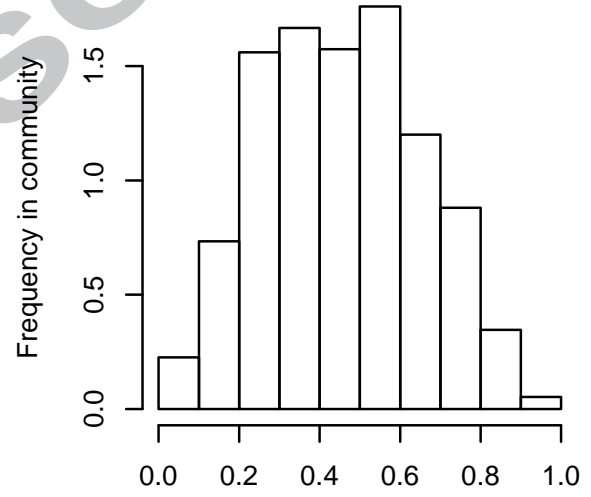

Proportion $\alpha_{C}$ of benthic sources in diet

F. Gradient of $\delta^{13} \mathrm{C}$ in consummers

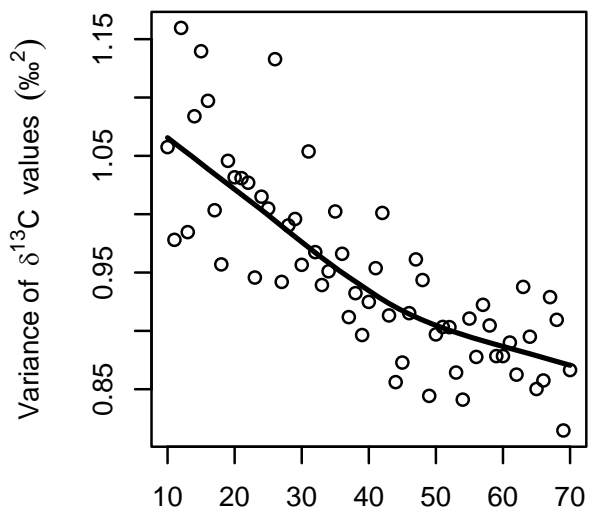

Depth (m) 


\begin{tabular}{|c|c|c|c|c|c|c|c|}
\hline & Code & Zone & $\mathrm{n}$ & $\delta^{13} \mathrm{C}(\%) \pm \mathrm{SD}$ & $\delta^{15} \mathrm{~N}(\%) \pm \mathrm{SD}$ & $\mathrm{TL} \pm \mathrm{SE}$ & Benthic fraction \pm SE \\
\hline \multicolumn{8}{|l|}{ Organic matter sources } \\
\hline \multirow[t]{2}{*}{ POM } & $\mathrm{PO}$ & All depths & 22 & $-21.53 \pm 1.32$ & $7.55 \pm 2.35$ & $1.76 \pm 0.16$ & $0.16 \pm 0.10$ \\
\hline & & $0-20 m$ & 22 & $-21.53 \pm 1.32$ & $7.55 \pm 2.35$ & $1.76 \pm 0.16$ & $0.16 \pm 0.10$ \\
\hline \multicolumn{8}{|l|}{ Zooplankton } \\
\hline \multirow[t]{2}{*}{ Chaetognaths } & CA & All depths & 3 & $-19.46 \pm 0.99$ & $12.70 \pm 0.70$ & $3.28 \pm 0.19$ & $0.12 \pm 0.16$ \\
\hline & & ग0-19ा1 & & $2107+0.09$ & $12.10 \pm 0.10$ & 0.2010 .10 & $0.1< \pm 0.10$ \\
\hline \multirow[t]{3}{*}{ Copepods } & $\mathrm{CO}$ & All depths & 11 & $-21.07 \pm 0.89$ & $10.28 \pm 1.70$ & $2.56 \pm 0.17$ & $0.00 \pm 0.10$ \\
\hline & & $20-38 m$ & 6 & $-21.43 \pm 0.77$ & $9.68 \pm 1.51$ & $2.28 \pm 0.19$ & $0.01 \pm 0.11$ \\
\hline & & $38-79 m$ & 5 & $-20.64 \pm 0.90$ & $11.00 \pm 1.78$ & $2.67 \pm 0.25$ & $0.06 \pm 0.14$ \\
\hline \multirow[t]{2}{*}{ Fish larvae } & $\mathrm{FI}$ & All depths & 4 & $-20.03 \pm 0.42$ & $12.89 \pm 0.09$ & $3.33 \pm 0.16$ & $-0.02 \pm 0.11$ \\
\hline & & $38-79 m$ & 4 & $-20.03 \pm 0.42$ & $12.89 \pm 0.09$ & $3.33 \pm 0.16$ & $-0.02 \pm 0.11$ \\
\hline \multicolumn{8}{|l|}{ Crustaceans } \\
\hline \multirow[t]{2}{*}{ Crangon crangon } & $\mathrm{CC}$ & All depths & 12 & $-16.05 \pm 1.08$ & $14.57 \pm 0.93$ & $3.83 \pm 0.23$ & $0.69 \pm 0.13$ \\
\hline & & $20-38 m$ & 12 & $-16.05 \pm 1.08$ & $14.57 \pm 0.93$ & $3.83 \pm 0.23$ & $0.69 \pm 0.13$ \\
\hline \multirow{2}{*}{ Liocarcinus holsatus } & LH & All depths & 14 & $-17.56 \pm 1.46$ & $13.10 \pm 0.99$ & $3.40 \pm 0.18$ & $0.50 \pm 0.12$ \\
\hline & & $20-38 m$ & 12 & $-17.67 \pm 1.54$ & $13.00 \pm 0.99$ & $3.26 \pm 0.17$ & $0.52 \pm 0.13$ \\
\hline \multirow[t]{2}{*}{ Maja brachydactyla } & MB & All depths & 8 & $-16.54 \pm 1.00$ & $13.66 \pm 0.93$ & $3.56 \pm 0.21$ & $0.66 \pm 0.13$ \\
\hline & & $20-38 m$ & 7 & $-16.58 \pm 1.07$ & $13.43 \pm 0.70$ & $3.38 \pm 0.18$ & $0.72 \pm 0.12$ \\
\hline \multirow[t]{3}{*}{ Necora puber } & NP & All depths & 18 & $-17.84 \pm 1.19$ & $13.95 \pm 0.69$ & $3.64 \pm 0.20$ & $0.35 \pm 0.12$ \\
\hline & & $0-20 m$ & 8 & $-17.79 \pm 1.37$ & $14.09 \pm 0.65$ & $3.58 \pm 0.19$ & $0.39 \pm 0.15$ \\
\hline & & $20-38 m$ & 10 & $-17.87 \pm 1.11$ & $13.84 \pm 0.74$ & $3.50 \pm 0.19$ & $0.39 \pm 0.12$ \\
\hline \multirow[t]{3}{*}{ Palaemon serratus } & PS & All depths & 7 & $-16.30 \pm 0.40$ & $15.86 \pm 1.11$ & $4.20 \pm 0.29$ & $0.51 \pm 0.14$ \\
\hline & & $20-38 m$ & 4 & $-16.17 \pm 0.47$ & $16.15 \pm 0.73$ & $4.18 \pm 0.27$ & $0.54 \pm 0.14$ \\
\hline & & $38-79 m$ & 3 & $-16.47 \pm 0.26$ & $15.47 \pm 1.59$ & $3.98 \pm 0.35$ & $0.54 \pm 0.15$ \\
\hline \multirow[t]{2}{*}{ Processa } & PR & All depths & 6 & $-15.78 \pm 0.42$ & $12.72 \pm 0.34$ & $3.28 \pm 0.16$ & $0.92 \pm 0.09$ \\
\hline & & $20-38 m$ & 6 & $-15.78 \pm 0.42$ & $12.72 \pm 0.34$ & $3.28 \pm 0.16$ & $0.92 \pm 0.09$ \\
\hline Paguroidea & PA & All depths & 3 & $-16.49 \pm 0.80$ & $12.44 \pm 0.22$ & $3.20 \pm 0.15$ & $0.80 \pm 0.13$ \\
\hline \multicolumn{8}{|l|}{ Echinoderms } \\
\hline \multirow[t]{2}{*}{ Psammechinus miliaris } & PM & All depths & 5 & $-20.09 \pm 1.45$ & $9.30 \pm 0.43$ & $2.28 \pm 0.08$ & $0.31 \pm 0.15$ \\
\hline & & & 5 & $-20.09 \pm 1.45$ & $9.30 \pm 0.43$ & $2.28 \pm 0.08$ & $0.31 \pm 0.15$ \\
\hline \multicolumn{8}{|l|}{ Polychaetes } \\
\hline \multirow[t]{2}{*}{ Nereis sp. } & NE & All depths & 4 & $-18.75 \pm 1.31$ & $11.44 \pm 0.52$ & $2.91 \pm 0.14$ & $0.40 \pm 0.16$ \\
\hline & & $20-38 m$ & 4 & $-18.75 \pm 1.31$ & $11.44 \pm 0.52$ & $2.91 \pm 0.14$ & $0.40 \pm 0.16$ \\
\hline Molluscs & & & & & & & \\
\hline Aequipecten oper & $\mathrm{AO}$ & All depths & 19 & $-17.36 \pm 0.32$ & $8.36 \pm 0.76$ & $2.00 \pm 0.07$ & $1.00 \pm 0.03$ \\
\hline & & $20-38 m$ & 6 & $-17.26 \pm 0.29$ & $9.32 \pm 0.20$ & $2.18 \pm 0.04$ & $0.96 \pm 0.03$ \\
\hline & & $38-79 m$ & 6 & $-17.47 \pm 0.31$ & $8.12 \pm 0.30$ & $1.82 \pm 0.05$ & $1.03 \pm 0.04$ \\
\hline Alloteuthis sp. & $A L$ & All depths & 8 & $-17.14 \pm 0.55$ & $16.06 \pm 0.83$ & $4.26 \pm 0.28$ & $0.30 \pm 0.15$ \\
\hline & & $38-79 m$ & 7 & $-17.24 \pm 0.52$ & $15.96 \pm 0.85$ & $4.13 \pm 0.26$ & $0.33 \pm 0.14$ \\
\hline Buccinum undatum & $\mathrm{BU}$ & All depths & 6 & $-15.48 \pm 0.32$ & $11.19 \pm 1.09$ & $2.83 \pm 0.17$ & $1.14 \pm 0.07$ \\
\hline & & $20-38 m$ & 6 & $-15.48 \pm 0.32$ & $11.19 \pm 1.09$ & $2.83 \pm 0.17$ & $1.14 \pm 0.07$ \\
\hline Crepidula fornicata & CF & All depths & 6 & $-18.04 \pm 0.31$ & $7.92 \pm 0.67$ & $1.87 \pm 0.10$ & $0.89 \pm 0.05$ \\
\hline & & $20-38 m$ & 6 & $-18.04 \pm 0.31$ & $7.92 \pm 0.67$ & $1.87 \pm 0.10$ & $0.89 \pm 0.05$ \\
\hline Glycymeris glycymeris & GL & All depths & 8 & $-17.68 \pm 0.97$ & $9.58 \pm 1.09$ & $2.36 \pm 0.13$ & $0.81 \pm 0.09$ \\
\hline & & $20-38 m$ & 8 & $-17.68 \pm 0.97$ & $9.58 \pm 1.09$ & $2.36 \pm 0.13$ & $0.81 \pm 0.09$ \\
\hline Laevicardium crassum & LC & All depths & 4 & $-19.03 \pm 0.96$ & $9.26 \pm 1.15$ & $2.27 \pm 0.18$ & $0.55 \pm 0.12$ \\
\hline & & $20-38 m$ & 4 & $-19.03 \pm 0.96$ & $9.26 \pm 1.15$ & $2.27 \pm 0.18$ & $0.55 \pm 0.12$ \\
\hline Loligo vulgaris & LV & All depths & 7 & $-16.82 \pm 0.97$ & $17.05 \pm 0.35$ & $4.56 \pm 0.30$ & $0.28 \pm 0.17$ \\
\hline & & $20-38 m$ & 6 & $-16.54 \pm 0.68$ & $16.98 \pm 0.33$ & $4.43 \pm 0.28$ & $0.38 \pm 0.16$ \\
\hline Mimachlamys varia & MI & All depths & 4 & $-17.89 \pm 0.51$ & $8.41 \pm 0.32$ & $2.01 \pm 0.07$ & $0.88 \pm 0.06$ \\
\hline Pecten maximus & PE & All depths & 5 & $-18.18 \pm 0.62$ & $8.27 \pm 0.35$ & $1.97 \pm 0.07$ & $0.83 \pm 0.07$ \\
\hline & & $20-38 m$ & 5 & $-18.18 \pm 0.62$ & $8.27 \pm 0.35$ & $1.97 \pm 0.07$ & $0.83 \pm 0.07$ \\
\hline Sepia officinalis & SO & All depths & 3 & $-16.93 \pm 0.21$ & $15.35 \pm 0.25$ & $4.06 \pm 0.24$ & $0.42 \pm 0.13$ \\
\hline Fishes & & & & & & & \\
\hline Aspitrigla cuculus & $A C$ & All depths & 18 & $-17.01 \pm 0.53$ & $14.58 \pm 0.55$ & $3.83 \pm 0.22$ & $0.47 \pm 0.11$ \\
\hline
\end{tabular}




\begin{tabular}{|c|c|c|c|c|c|c|c|}
\hline & & $20-38 m$ & 9 & $-16.54 \pm 0.21$ & $14.72 \pm 0.38$ & $3.76 \pm 0.21$ & $0.60 \pm 0.11$ \\
\hline & & $38-79 m$ & 9 & $-17.48 \pm 0.23$ & $14.45 \pm 0.67$ & $3.68 \pm 0.20$ & $0.42 \pm 0.11$ \\
\hline \multirow[t]{2}{*}{ Buglossidium luteum } & $\mathrm{BL}$ & All depths & 7 & $-16.79 \pm 0.56$ & $13.65 \pm 0.81$ & $3.56 \pm 0.21$ & $0.61 \pm 0.11$ \\
\hline & & $20-38 m$ & 6 & $-16.59 \pm 0.18$ & $13.40 \pm 0.53$ & $3.38 \pm 0.17$ & $0.72 \pm 0.09$ \\
\hline \multirow[t]{3}{*}{ Callionymus lyra } & $\mathrm{CL}$ & All depths & 18 & $-17.31 \pm 1.22$ & $13.37 \pm 0.78$ & $3.47 \pm 0.18$ & $0.52 \pm 0.11$ \\
\hline & & $0-20 m$ & 7 & $-16.34 \pm 0.75$ & $12.64 \pm 0.50$ & $3.15 \pm 0.14$ & $0.84 \pm 0.09$ \\
\hline & & $20-38 m$ & 9 & $-18.04 \pm 1.16$ & $13.98 \pm 0.48$ & $3.55 \pm 0.19$ & $0.34 \pm 0.13$ \\
\hline \multirow[t]{3}{*}{ Chelidonichthys lucerna } & TU & All depths & 11 & $-17.44 \pm 0.60$ & $15.74 \pm 1.03$ & $4.17 \pm 0.27$ & $0.27 \pm 0.14$ \\
\hline & & $0-20 m$ & 4 & $-17.51 \pm 0.61$ & $16.21 \pm 0.26$ & $4.20 \pm 0.26$ & $0.24 \pm 0.15$ \\
\hline & & $20-38 m$ & 6 & $-17.34 \pm 0.67$ & $15.17 \pm 1.01$ & $3.90 \pm 0.25$ & $0.38 \pm 0.14$ \\
\hline \multirow[t]{3}{*}{ Clupea harengus } & $\mathrm{CH}$ & All depths & 10 & $-18.05 \pm 1.72$ & $13.53 \pm 1.69$ & $3.52 \pm 0.24$ & $0.35 \pm 0.16$ \\
\hline & & $0-20 m$ & 5 & $-16.74 \pm 0.29$ & $12.92 \pm 0.37$ & $3.23 \pm 0.15$ & $0.73 \pm 0.08$ \\
\hline & & $20-38 m$ & 4 & $-19.02 \pm 1.48$ & $14.47 \pm 2.54$ & $3.69 \pm 0.42$ & $0.08 \pm 0.23$ \\
\hline \multirow[t]{4}{*}{ Dicentrarchus labrax } & $\mathrm{DL}$ & All depths & 52 & $-16.67 \pm 0.83$ & $15.84 \pm 0.93$ & $4.20 \pm 0.26$ & $0.43 \pm 0.13$ \\
\hline & & $0-20 m$ & 18 & $-16.85 \pm 0.74$ & $15.49 \pm 0.77$ & $3.99 \pm 0.24$ & $0.46 \pm 0.13$ \\
\hline & & $20-38 m$ & 27 & $-16.51 \pm 0.95$ & $16.04 \pm 1.08$ & $4.15 \pm 0.25$ & $0.48 \pm 0.13$ \\
\hline & & $38-79 m$ & 7 & $-16.81 \pm 0.46$ & $16.00 \pm 0.34$ & $4.14 \pm 0.25$ & $0.41 \pm 0.13$ \\
\hline \multirow[t]{3}{*}{ Eutrigla gurnardus } & EG & All depths & 12 & $-16.96 \pm 0.68$ & $14.80 \pm 0.67$ & $3.89 \pm 0.23$ & $0.46 \pm 0.12$ \\
\hline & & $0-20 m$ & 4 & $-16.80 \pm 0.95$ & $15.02 \pm 0.49$ & $3.85 \pm 0.22$ & $0.51 \pm 0.15$ \\
\hline & & $20-38 m$ & 7 & $-16.86 \pm 0.27$ & $14.47 \pm 0.48$ & $3.69 \pm 0.20$ & $0.55 \pm 0.10$ \\
\hline \multirow[t]{4}{*}{ Gadus morhua } & GM & All depths & 36 & $-16.55 \pm 0.57$ & $15.37 \pm 1.06$ & $4.06 \pm 0.25$ & $0.50 \pm 0.13$ \\
\hline & & $0-20 m$ & 7 & $-16.94 \pm 0.43$ & $16.25 \pm 0.94$ & $4.21 \pm 0.28$ & $0.36 \pm 0.14$ \\
\hline & & $20-38 m$ & 23 & $-16.55 \pm 0.47$ & $14.95 \pm 0.96$ & $3.83 \pm 0.22$ & $0.57 \pm 0.11$ \\
\hline & & $38-79 m$ & 6 & $-16.10 \pm 0.77$ & $15.95 \pm 0.69$ & $4.13 \pm 0.26$ & $0.57 \pm 0.14$ \\
\hline \multirow[t]{2}{*}{ Galeorhinus galeus } & GG & All depths & 3 & $-16.62 \pm 0.14$ & $16.24 \pm 0.21$ & $4.32 \pm 0.27$ & $0.40 \pm 0.14$ \\
\hline & & $38-79 m$ & 3 & $-16.62 \pm 0.14$ & $16.24 \pm 0.21$ & $4.21 \pm 0.26$ & $0.43 \pm 0.13$ \\
\hline \multirow[t]{3}{*}{ Gobiidae } & GO & All depths & 10 & $-17.71 \pm 0.60$ & $14.70 \pm 0.69$ & $3.86 \pm 0.23$ & $0.31 \pm 0.12$ \\
\hline & & $0-20 m$ & & $-18.02 \pm 0.30$ & $14.52 \pm 0.31$ & $3.71 \pm 0.20$ & $0.29 \pm 0.11$ \\
\hline & & $20-38 m$ & & $-16.98 \pm 0.45$ & $15.12 \pm 1.22$ & $3.88 \pm 0.30$ & $0.46 \pm 0.14$ \\
\hline \multirow[t]{2}{*}{ Hyperoplus lanceolatus } & $\mathrm{HL}$ & All depths & 5 & $-16.72 \pm 0.28$ & $14.89 \pm 0.57$ & $3.92 \pm 0.24$ & $0.51 \pm 0.12$ \\
\hline & & $0-20 m$ & 5 & $-16.72 \pm 0.28$ & $14.89 \pm 0.57$ & $3.81 \pm 0.22$ & $0.54 \pm 0.11$ \\
\hline \multirow[t]{3}{*}{ Limanda limanda } & LL & All depths & 18 & $-16.66 \pm 0.90$ & $12.81 \pm 0.57$ & $3.31 \pm 0.16$ & $0.72 \pm 0.09$ \\
\hline & & $0-20 m$ & 3 & $-17.29 \pm 0.24$ & $13.11 \pm 0.43$ & $3.29 \pm 0.17$ & $0.59 \pm 0.09$ \\
\hline & & $20-38 m$ & 14 & $-16.52 \pm 0.97$ & $12.74 \pm 0.60$ & $3.18 \pm 0.14$ & $0.79 \pm 0.09$ \\
\hline \multirow[t]{4}{*}{ Merlangius merlangus } & MM & All depths & 48 & $-16.57 \pm 0.44$ & $16.05 \pm 0.53$ & $4.26 \pm 0.26$ & $0.43 \pm 0.13$ \\
\hline & & $0-20 m$ & 5 & $-16.71 \pm 0.92$ & $16.13 \pm 1.03$ & $4.18 \pm 0.28$ & $0.42 \pm 0.16$ \\
\hline & & $20-38 m$ & 34 & $-16.53 \pm 0.38$ & $16.06 \pm 0.48$ & $4.16 \pm 0.25$ & $0.47 \pm 0.13$ \\
\hline & & $38-79 m$ & 9 & $-16.66 \pm 0.33$ & $15.96 \pm 0.37$ & $4.13 \pm 0.25$ & $0.45 \pm 0.13$ \\
\hline \multirow{2}{*}{ Microstomus kitt } & MK & All depths & 15 & $-16.58 \pm 0.66$ & $13.38 \pm 0.58$ & $3.48 \pm 0.18$ & $0.68 \pm 0.10$ \\
\hline & & $20-38 m$ & 13 & $-16.50 \pm 0.47$ & $13.31 \pm 0.53$ & $3.35 \pm 0.16$ & $0.74 \pm 0.09$ \\
\hline \multirow{2}{*}{ Micromesistius poutassou } & MP & All depths & 12 & $-18.26 \pm 0.68$ & $11.64 \pm 1.38$ & $2.96 \pm 0.17$ & $0.49 \pm 0.09$ \\
\hline & & $38-79 m$ & 12 & $-18.26 \pm 0.68$ & $11.64 \pm 1.38$ & $2.96 \pm 0.17$ & $0.49 \pm 0.09$ \\
\hline \multirow[t]{2}{*}{ Microchirus variegatus } & MV & All depths & 6 & $-15.65 \pm 0.21$ & $14.28 \pm 0.20$ & $3.74 \pm 0.21$ & $0.80 \pm 0.10$ \\
\hline & & $20-38 m$ & 6 & $-15.65 \pm 0.21$ & $14.28 \pm 0.20$ & $3.74 \pm 0.21$ & $0.80 \pm 0.10$ \\
\hline \multirow[t]{4}{*}{ Mullus surmuletus } & MS & All depths & 72 & $-17.58 \pm 0.69$ & $15.04 \pm 0.80$ & $3.96 \pm 0.23$ & $0.30 \pm 0.12$ \\
\hline & & $0-20 m$ & 8 & $-17.09 \pm 1.07$ & $14.54 \pm 0.91$ & $3.71 \pm 0.22$ & $0.50 \pm 0.14$ \\
\hline & & $20-38 m$ & 46 & $-17.60 \pm 0.61$ & $15.04 \pm 0.78$ & $3.86 \pm 0.22$ & $0.34 \pm 0.12$ \\
\hline & & $38-79 m$ & 18 & $-17.77 \pm 0.63$ & $15.24 \pm 0.75$ & $3.92 \pm 0.23$ & $0.28 \pm 0.12$ \\
\hline \multirow[t]{3}{*}{ Mustelus sp. } & MU & All depths & 14 & $-16.28 \pm 0.70$ & $13.51 \pm 1.59$ & $3.51 \pm 0.22$ & $0.74 \pm 0.11$ \\
\hline & & $20-38 m$ & 8 & $-16.49 \pm 0.31$ & $12.79 \pm 0.49$ & $3.20 \pm 0.15$ & $0.80 \pm 0.08$ \\
\hline & & $38-79 m$ & 6 & $-16.01 \pm 1.00$ & $14.47 \pm 2.08$ & $3.69 \pm 0.32$ & $0.74 \pm 0.16$ \\
\hline \multirow[t]{2}{*}{ Platichthys flesus } & PF & All depths & 10 & $-17.38 \pm 0.52$ & $13.88 \pm 0.78$ & $3.62 \pm 0.21$ & $0.46 \pm 0.11$ \\
\hline & & $0-20 m$ & 9 & $-17.35 \pm 0.54$ & $13.97 \pm 0.78$ & $3.54 \pm 0.20$ & $0.49 \pm 0.10$ \\
\hline Pleuronectes platessa & PP & All depths & 46 & $-16.61 \pm 0.82$ & $13.41 \pm 1.02$ & $3.49 \pm 0.18$ & $0.68 \pm 0.09$ \\
\hline & & $0-20 m$ & 11 & $-17.12 \pm 0.64$ & $13.85 \pm 0.43$ & $3.51 \pm 0.18$ & $0.56 \pm 0.10$ \\
\hline
\end{tabular}




\begin{tabular}{|c|c|c|c|c|c|c|c|}
\hline & & $20-38 m$ & 34 & $-16.47 \pm 0.81$ & $13.32 \pm 1.09$ & $3.35 \pm 0.17$ & $0.75 \pm 0.09$ \\
\hline Psetta maxima & PT & All depths & 5 & $-17.18 \pm 0.63$ & $16.29 \pm 0.62$ & $4.33 \pm 0.28$ & $0.27 \pm 0.16$ \\
\hline \multirow[t]{4}{*}{ Raja clavata } & $\mathrm{RC}$ & All depths & 32 & $-15.93 \pm 0.73$ & $13.66 \pm 0.89$ & $3.56 \pm 0.19$ & $0.80 \pm 0.10$ \\
\hline & & $0-20 m$ & 8 & $-16.58 \pm 0.65$ & $14.61 \pm 0.69$ & $3.73 \pm 0.21$ & $0.60 \pm 0.12$ \\
\hline & & $20-38 m$ & 18 & $-15.70 \pm 0.65$ & $13.58 \pm 0.49$ & $3.43 \pm 0.17$ & $0.89 \pm 0.09$ \\
\hline & & $38-79 m$ & 6 & $-15.78 \pm 0.58$ & $12.64 \pm 0.84$ & $3.15 \pm 0.17$ & $0.97 \pm 0.09$ \\
\hline \multirow[t]{3}{*}{ Sardina pilchardus } & SP & All depths & 10 & $-17.89 \pm 1.34$ & $12.72 \pm 1.34$ & $3.28 \pm 0.20$ & $0.46 \pm 0.13$ \\
\hline & & $0-20 m$ & 4 & $-16.70 \pm 0.44$ & $12.99 \pm 1.09$ & $3.25 \pm 0.22$ & $0.73 \pm 0.10$ \\
\hline & & $20-38 m$ & 6 & $-18.69 \pm 1.12$ & $12.55 \pm 1.57$ & $3.12 \pm 0.23$ & $0.34 \pm 0.14$ \\
\hline \multirow[t]{3}{*}{ Scomber scombrus } & SS & All depths & 48 & $-18.56 \pm 1.63$ & $14.57 \pm 1.21$ & $3.83 \pm 0.22$ & $0.13 \pm 0.13$ \\
\hline & & $0-20 m$ & 29 & $-18.28 \pm 1.95$ & $15.18 \pm 1.00$ & $3.90 \pm 0.23$ & $0.17 \pm 0.14$ \\
\hline & & $20-38 m$ & 18 & $-19.04 \pm 0.82$ & $13.58 \pm 0.85$ & $3.43 \pm 0.18$ & $0.16 \pm 0.11$ \\
\hline \multirow[t]{2}{*}{ Scophthalmus rhombus } & SR & All depths & 10 & $-17.09 \pm 0.81$ & $15.43 \pm 0.45$ & $4.08 \pm 0.25$ & $0.37 \pm 0.14$ \\
\hline & & $0-20 m$ & 8 & $-16.95 \pm 0.84$ & $15.51 \pm 0.24$ & $4.00 \pm 0.23$ & $0.43 \pm 0.14$ \\
\hline \multirow[t]{3}{*}{ Scyliorhinus canicula } & SY & All depths & 48 & $-16.36 \pm 0.64$ & $14.44 \pm 0.87$ & $3.79 \pm 0.21$ & $0.63 \pm 0.11$ \\
\hline & & $20-38 m$ & 40 & $-16.36 \pm 0.68$ & $14.52 \pm 0.88$ & $3.70 \pm 0.20$ & $0.66 \pm 0.10$ \\
\hline & & $38-79 m$ & 8 & $-16.37 \pm 0.37$ & $14.04 \pm 0.71$ & $3.56 \pm 0.19$ & $0.70 \pm 0.10$ \\
\hline \multirow[t]{2}{*}{ Scyliorhinus stellaris } & SE & All depths & 10 & $-16.83 \pm 0.39$ & $13.33 \pm 1.38$ & $3.46 \pm 0.22$ & $0.63 \pm 0.10$ \\
\hline & & $38-79 m$ & 9 & $-16.76 \pm 0.35$ & $13.01 \pm 0.99$ & $3.26 \pm 0.18$ & $0.71 \pm 0.09$ \\
\hline \multirow[t]{4}{*}{ Solea solea } & SL & All depths & 54 & $-16.75 \pm 0.80$ & $13.90 \pm 1.00$ & $3.63 \pm 0.20$ & $0.60 \pm 0.10$ \\
\hline & & $0-20 m$ & 16 & $-17.21 \pm 0.96$ & $14.19 \pm 0.73$ & $3.61 \pm 0.19$ & $0.50 \pm 0.11$ \\
\hline & & $20-38 m$ & 32 & $-16.51 \pm 0.63$ & $13.69 \pm 0.96$ & $3.46 \pm 0.18$ & $0.70 \pm 0.09$ \\
\hline & & $38-79 m$ & 6 & $-16.76 \pm 0.73$ & $14.28 \pm 1.64$ & $3.63 \pm 0.27$ & $0.59 \pm 0.13$ \\
\hline \multirow[t]{3}{*}{ Spondyliosoma cantharus } & SC & All depths & 15 & $-19.02 \pm 1.28$ & $15.11 \pm 0.24$ & $3.98 \pm 0.23$ & $-0.02 \pm 0.15$ \\
\hline & & $0-20 m$ & 5 & $-20.12 \pm 1.49$ & $14.98 \pm 0.16$ & $3.84 \pm 0.21$ & $-0.21 \pm 0.19$ \\
\hline & & $20-38 m$ & 8 & $-18.61 \pm 0.76$ & $15.13 \pm 0.18$ & $3.89 \pm 0.22$ & $0.10 \pm 0.13$ \\
\hline \multirow[t]{2}{*}{ Sprattus sprattus } & SA & All depths & 10 & $-18.10 \pm 1.15$ & $13.16 \pm 0.32$ & $3.41 \pm 0.17$ & $0.37 \pm 0.12$ \\
\hline & & $20-38 m$ & 9 & $-18.30 \pm 1.03$ & $13.13 \pm 0.33$ & $3.30 \pm 0.16$ & $0.37 \pm 0.11$ \\
\hline \multirow[t]{4}{*}{ Trachurus trachurus } & TT & All depths & 57 & $-18.05 \pm 1.04$ & $16.16 \pm 1.18$ & $4.29 \pm 0.27$ & $0.09 \pm 0.15$ \\
\hline & & $0-20 m$ & 7 & $-17.89 \pm 0.92$ & $16.82 \pm 1.31$ & $4.38 \pm 0.31$ & $0.10 \pm 0.17$ \\
\hline & & $20-38 m$ & 33 & $-18.01 \pm 1.20$ & $16.22 \pm 0.81$ & $4.21 \pm 0.26$ & $0.13 \pm 0.14$ \\
\hline & & $38-79 m$ & 17 & $-18.18 \pm 0.75$ & $15.76 \pm 1.58$ & $4.07 \pm 0.26$ & $0.14 \pm 0.14$ \\
\hline \multirow[t]{3}{*}{ Trigloporus lastowiza } & TA & All depths & 10 & $-17.67 \pm 0.35$ & $13.35 \pm 0.40$ & $3.47 \pm 0.18$ & $0.45 \pm 0.10$ \\
\hline & & $20-38 m$ & 3 & $-17.44 \pm 0.35$ & $13.52 \pm 0.59$ & $3.41 \pm 0.19$ & $0.52 \pm 0.10$ \\
\hline & & $38-79 m$ & 7 & $-17.77 \pm 0.32$ & $13.28 \pm 0.32$ & $3.34 \pm 0.16$ & $0.47 \pm 0.09$ \\
\hline \multirow[t]{2}{*}{ Trisopterus luscus } & TL & All depths & 24 & $-17.34 \pm 1.20$ & $14.78 \pm 0.86$ & $3.89 \pm 0.23$ & $0.38 \pm 0.13$ \\
\hline & & $20-38 m$ & 24 & $-17.34 \pm 1.20$ & $14.78 \pm 0.86$ & $3.89 \pm 0.23$ & $0.38 \pm 0.13$ \\
\hline \multirow[t]{3}{*}{ Trisopterus minutus } & TM & All depths & 15 & $-17.63 \pm 1.29$ & $14.57 \pm 0.52$ & $3.83 \pm 0.22$ & $0.34 \pm 0.13$ \\
\hline & & $20-38 m$ & 11 & $-17.73 \pm 1.30$ & $14.69 \pm 0.55$ & $3.76 \pm 0.21$ & $0.34 \pm 0.14$ \\
\hline & & $38-79 m$ & 3 & $-17.70 \pm 1.49$ & $14.17 \pm 0.30$ & $3.60 \pm 0.19$ & $0.40 \pm 0.21$ \\
\hline \multirow[t]{4}{*}{ Zeus faber } & ZF & All depths & 13 & $-17.07 \pm 0.79$ & $14.67 \pm 0.68$ & $3.85 \pm 0.22$ & $0.45 \pm 0.12$ \\
\hline & & $0-20 m$ & 3 & $-16.88 \pm 1.25$ & $15.06 \pm 0.66$ & $3.86 \pm 0.24$ & $0.49 \pm 0.20$ \\
\hline & & $20-38 m$ & 6 & $-16.87 \pm 0.40$ & $14.30 \pm 0.65$ & $3.64 \pm 0.20$ & $0.57 \pm 0.11$ \\
\hline & & $38-79 \mathrm{~m}$ & 4 & $-17.49 \pm 0.91$ & $14.93 \pm 0.60$ & $3.82 \pm 0.23$ & $0.37 \pm 0.15$ \\
\hline
\end{tabular}

